\title{
Reactive Oxygen Species, Oxidative Damage, and Antioxidative Defense Mechanism in Plants under Stressful Conditions
}

\author{
Pallavi Sharma, ${ }^{1}$ Ambuj Bhushan Jha, ${ }^{2}$ Rama Shanker Dubey, ${ }^{1}$ and Mohammad Pessarakli ${ }^{3}$ \\ ${ }^{1}$ Department of Biochemistry, Faculty of Science, Banaras Hindu University, Varanasi 221005, India \\ ${ }^{2}$ Crop Development Centre, Department of Plant Sciences, College of Agriculture and Bioresources, University of Saskatchewan, \\ 51 Campus Drive, Saskatoon SK, Canada SK S7N 5 A8 \\ ${ }^{3}$ School of Plant Sciences, The University of Arizona, Forbes Building, Room 303, P.O. Box 210036, Tucson, AZ 85721-0036, USA
}

Correspondence should be addressed to Mohammad Pessarakli, pessarak@email.arizona.edu

Received 6 August 2011; Revised 12 February 2012; Accepted 12 February 2012

Academic Editor: Andrea Polle

Copyright (C) 2012 Pallavi Sharma et al. This is an open access article distributed under the Creative Commons Attribution License, which permits unrestricted use, distribution, and reproduction in any medium, provided the original work is properly cited.

\begin{abstract}
Reactive oxygen species (ROS) are produced as a normal product of plant cellular metabolism. Various environmental stresses lead to excessive production of ROS causing progressive oxidative damage and ultimately cell death. Despite their destructive activity, they are well-described second messengers in a variety of cellular processes, including conferment of tolerance to various environmental stresses. Whether ROS would serve as signaling molecules or could cause oxidative damage to the tissues depends on the delicate equilibrium between ROS production, and their scavenging. Efficient scavenging of ROS produced during various environmental stresses requires the action of several nonenzymatic as well as enzymatic antioxidants present in the tissues. In this paper, we describe the generation, sites of production and role of ROS as messenger molecules as well as inducers of oxidative damage. Further, the antioxidative defense mechanisms operating in the cells for scavenging of ROS overproduced under various stressful conditions of the environment have been discussed in detail.
\end{abstract}

\section{Introduction}

An unavoidable consequence of aerobic metabolism is production of reactive oxygen species (ROS). ROS include free radicals such as superoxide anion $\left(\mathrm{O}_{2}{ }^{\bullet-}\right)$, hydroxyl radical $(\bullet \mathrm{OH})$, as well as nonradical molecules like hydrogen peroxide $\left(\mathrm{H}_{2} \mathrm{O}_{2}\right)$, singlet oxygen $\left({ }^{1} \mathrm{O}_{2}\right)$, and so forth. Stepwise reduction of molecular oxygen $\left(\mathrm{O}_{2}\right)$ by high-energy exposure or electron-transfer reactions leads to production of the highly reactive ROS. In plants, ROS are always formed by the inevitable leakage of electrons onto $\mathrm{O}_{2}$ from the electron transport activities of chloroplasts, mitochondria, and plasma membranes or as a byproduct of various metabolic pathways localized in different cellular compartments [15]. Environmental stresses such as drought, salinity, chilling, metal toxicity, and UV-B radiation as well as pathogens attack lead to enhanced generation of ROS in plants due to disruption of cellular homeostasis [6-15]. All ROS are extremely harmful to organisms at high concentrations. When the level of ROS exceeds the defense mechanisms, a cell is said to be in a state of "oxidative stress." The enhanced production of ROS during environmental stresses can pose a threat to cells by causing peroxidation of lipids, oxidation of proteins, damage to nucleic acids, enzyme inhibition, activation of programmed cell death (PCD) pathway and ultimately leading to death of the cells $[6-8,11,13,14,16,17]$.

Despite their destructive activity, ROS are well-described second messengers in a variety of cellular processes including tolerance to environmental stresses [18-20]. Whether ROS will act as damaging or signaling molecule depends on the delicate equilibrium between ROS production and scavenging. Because of the multifunctional roles of ROS, it is necessary for the cells to control the level of ROS tightly to avoid any oxidative injury and not to eliminate them completely. Scavenging or detoxification of excess ROS is achieved by an efficient antioxidative system comprising of the nonenzymic as well as enzymic antioxidants [21]. The enzymic antioxidants include superoxide dismutase (SOD), catalase (CAT), guaiacol peroxidase (GPX), enzymes of ascorbateglutahione (AsA-GSH) cycle such as ascorbate peroxidase 
(APX), monodehydroascorbate reductase (MDHAR), dehydroascorbate reductase (DHAR), and glutathione reductase (GR) [21]. Ascorbate (AsA), glutathione (GSH), carotenoids, tocopherols, and phenolics serve as potent nonenzymic antioxidants within the cell. Various workers have reported increased activities of many enzymes of the antioxidant defense system in plants to combat oxidative stress induced by various environmental stresses. Maintenance of a high antioxidant capacity to scavenge the toxic ROS has been linked to increased tolerance of plants to these environmental stresses $[22,23]$. Considerable progress has been made in improving stress-induced oxidative stress tolerance in crop plants by developing transgenic lines with altered levels of antioxidants $[24,25]$. Simultaneous expression of multiple antioxidant enzymes has been shown to be more effective than single or double expression for developing transgenic plants with enhanced tolerance to multiple environmental stresses [26]. The present review focuses on types of ROS, their site of production, and their role as messenger and inducer of oxidative stress. Further, role of antioxidative defense system in combating danger posed by overproduced ROS under stresses has been discussed in detail.

\section{Reactive Oxygen Species, Sites of Production, and Their Effects}

ROS are a group of free radicals, reactive molecules, and ions that are derived from $\mathrm{O}_{2}$. It has been estimated that about $1 \%$ of $\mathrm{O}_{2}$ consumed by plants is diverted to produce ROS [27] in various subcellular loci such as chloroplasts, mitochondria, peroxisomes. ROS are well recognized for playing a dual role as both deleterious and beneficial species depending on their concentration in plants. At high concentration ROS cause damage to biomolecules, whereas at low/moderate concentration it acts as second messenger in intracellular signaling cascades that mediate several responses in plant cells.

2.1. Types of ROS. The most common ROS include ${ }^{1} \mathrm{O}_{2}$, $\mathrm{O}_{2}{ }^{\bullet-}, \mathrm{H}_{2} \mathrm{O}_{2},{ }^{\bullet} \mathrm{OH} . \mathrm{O}_{2}$ itself is a totally harmless molecule as in its ground state it has two unpaired electrons with parallel spin which makes it paramagnetic and, hence, unlikely to participate in reactions with organic molecules unless it is activated [28]. Activation of $\mathrm{O}_{2}$ may occur by two different mechanisms: (i) absorption of sufficient energy to reverse the spin on one of the unpaired electrons and (ii) stepwise monovalent reduction (Figure 1). In the former, ${ }^{1} \mathrm{O}_{2}$ is formed, whereas in latter, $\mathrm{O}_{2}$ is sequentially reduced to $\mathrm{O}_{2}{ }^{\cdot-}, \mathrm{H}_{2} \mathrm{O}_{2}$, and ${ }^{\bullet} \mathrm{OH}$ (Figure 1).

Electrons in the biradical form of oxygen have parallel spin. Absorption of sufficient energy reverses the spin of one of its unpaired electrons leading to formation of singlet state in which the two electrons have opposite spin. This activation overcomes the spin restriction and ${ }^{1} \mathrm{O}_{2}$ can consequently participate in reactions involving the simultaneous transfer of two electrons (divalent reduction) [28]. In the light, highly reactive ${ }^{1} \mathrm{O}_{2}$ can be produced via triplet chlorophyll (Chl) formation in the antenna system and in the reaction centre of photosystem II [29]. In the antenna, insufficient energy dissipation during photosynthesis can lead to formation of chlorophyll (Chl) triplet state, whereas in the reaction centre it is formed via charge recombination of the light-induced charge pair [29]. The Chl triplet state can react with ${ }^{3} \mathrm{O}_{2}$ to give up the very highly destructive $\operatorname{ROS}{ }^{1} \mathrm{O}_{2}$ :

$$
\begin{gathered}
\text { Chl } \stackrel{\text { light }}{\longrightarrow}{ }^{3} \mathrm{Chl}, \\
{ }^{3} \mathrm{Chl}+{ }^{3} \mathrm{O}_{2} \longrightarrow \mathrm{Chl}+{ }^{1} \mathrm{O}_{2},
\end{gathered}
$$

Further, limited $\mathrm{CO}_{2}$ availability due to closure of stomata during various environmental stresses such as salinity, drought favors the formation of ${ }^{1} \mathrm{O}_{2}$. The life time of ${ }^{1} \mathrm{O}_{2}$ within the cell is probably $3 \mu$ s or less [30,31]. A fraction of ${ }^{1} \mathrm{O}_{2}$ has been shown to be able to diffuse over considerable distances of several hundred nanometers $(\mathrm{nm}) .{ }^{1} \mathrm{O}_{2}$ can last for $4 \mu \mathrm{s}$ in water and $100 \mu \mathrm{s}$ in a nonpolar environment [1]. ${ }^{1} \mathrm{O}_{2}$ reacts with most of the biological molecules at near diffusion-controlled rates [1]. It directly oxidizes protein, unsaturated fatty acids, and DNA [32]. It causes nucleic acid modification through selective reaction with deoxyguanosine [33]. It is thought to be the most important species responsible for light-induced loss of photosystem II (PSII) activity which may trigger cell death [34]. ${ }^{1} \mathrm{O}_{2}$ can be quenched by $\beta$-carotene, $\alpha$-tocopherol or can react with the D1 protein of photosystem II as target [29].

Due to spin restriction, molecular $\mathrm{O}_{2}$ cannot accept four electrons at a time to produce $\mathrm{H}_{2} \mathrm{O}$. It accepts one electron at a time and hence during reduction of $\mathrm{O}_{2}$ stable intermediates are formed in the step-wise fashion [35]. $\mathrm{O}_{2}{ }^{-{ }^{-}}$is the primary ROS formed in the cell which initiates a cascade of reactions to generate "secondary" ROS, either directly or prevalently through enzyme- or metal-catalysed processes [36] depending on the cell type or cellular compartment. $\mathrm{O}_{2}{ }^{--}$is a moderately reactive, short-lived ROS with a halflife of approx. $1 \mu \mathrm{s} . \mathrm{O}_{2}{ }^{--}$is a nucleophilic reactant with both oxidizing and reducing properties [37]. Anionic charge of $\mathrm{O}_{2}{ }^{--}$inhibits its electrophilic activity toward electronrich molecules. $\mathrm{O}_{2}{ }^{--}$has been shown to oxidize enzymes containing the $[4 \mathrm{Fe}-4 \mathrm{~S}]$ clusters (aconitase or dehydratase as examples) [38] and reduce cytochrome $\mathrm{C}$ [39]. $\mathrm{O}_{2}{ }^{-{ }^{-}}$can accept one electron and two protons to form $\mathrm{H}_{2} \mathrm{O}_{2}$. It is easily dismutated to $\mathrm{H}_{2} \mathrm{O}_{2}$ either nonenzymatically or by SOD catalyzed reaction to hydrogen peroxide:

$$
\begin{aligned}
& 2 \mathrm{O}_{2}{ }^{--}+2 \mathrm{H}^{+} \longrightarrow \mathrm{H}_{2} \mathrm{O}_{2}+\mathrm{O}_{2}, \\
& 2 \mathrm{O}_{2}{ }^{\bullet-}+2 \mathrm{H}^{+} \stackrel{\text { SOD }}{\longrightarrow} \mathrm{H}_{2} \mathrm{O}_{2}+\mathrm{O}_{2},
\end{aligned}
$$

$\mathrm{H}_{2} \mathrm{O}_{2}$ is generated in the cells under normal as well as wide range of stressful conditions such as drought, chilling, UV irradiation, exposure to intense light, wounding and intrusion by pathogens. Electron transport chain (ETC) of chloroplast, mitochondria, endoplasmic reticulum and plasma membrane, $\beta$-oxidation of fatty acid and photorespiration are major sources of $\mathrm{H}_{2} \mathrm{O}_{2}$ generation in plant cells. Photooxidation reactions, NADPH oxidase as well as xanthine oxidase (XOD) also contribute to $\mathrm{H}_{2} \mathrm{O}_{2}$ production in plants. It is also generated in tissues requiring it as a substrate 


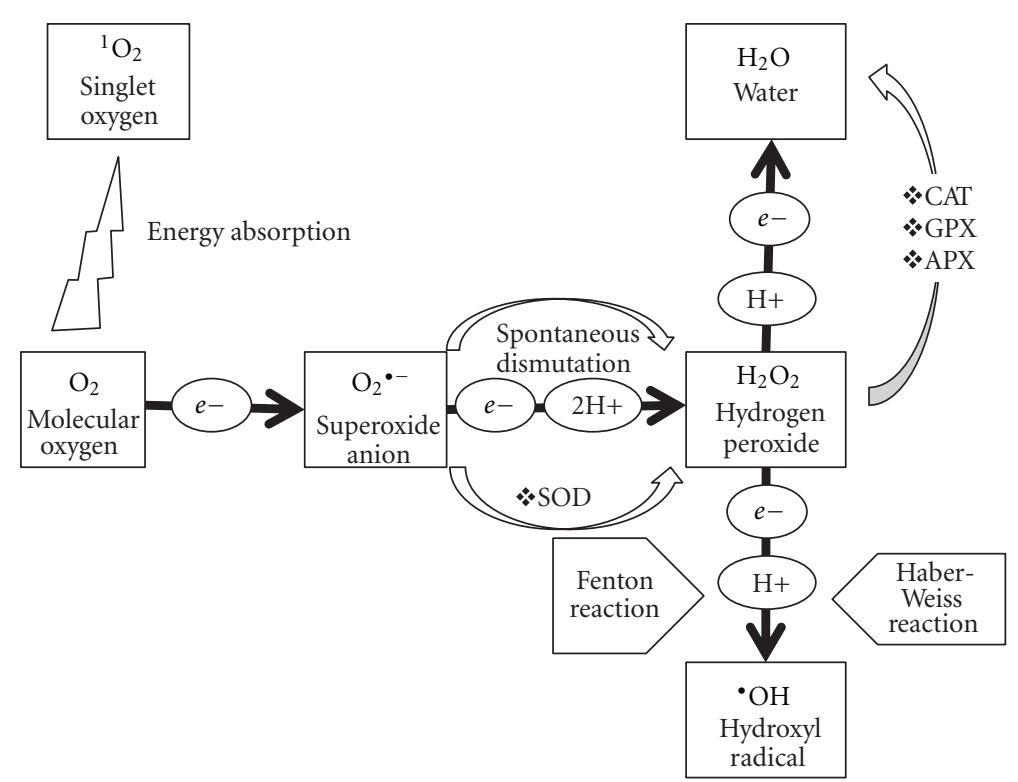

Figure 1: Schematic representation of generation of reactive oxygen species (ROS) in plants. Activation of $\mathrm{O}_{2}$ occurs by two different mechanisms. Stepwise monovalent reduction of $\mathrm{O}_{2}$ leads to formation of $\mathrm{O}_{2}{ }^{\bullet-}, \mathrm{H}_{2} \mathrm{O}_{2}$, and $\bullet \mathrm{OH}$, whereas energy transfer to $\mathrm{O}_{2}$ leads to formation of ${ }^{1} \mathrm{O}_{2} \cdot \mathrm{O}_{2}{ }^{\bullet-}$ is easily dismutated to $\mathrm{H}_{2} \mathrm{O}_{2}$ either nonenzymatically or by superoxide dismutase (SOD) catalyzed reaction to $\mathrm{H}_{2} \mathrm{O}_{2}$. $\mathrm{H}_{2} \mathrm{O}_{2}$ is converted to $\mathrm{H}_{2} \mathrm{O}$ by catalase (CAT), guaiacol peroxidase (GPX), and ascorbate peroxidase (APX).

for biosynthesis such as for lignification and suberization. $\mathrm{H}_{2} \mathrm{O}_{2}$ is moderately reactive and is relatively long-lived molecule with a half-life of $1 \mathrm{~ms}$ [40]. $\mathrm{H}_{2} \mathrm{O}_{2}$ has no unpaired electrons, unlike other oxygen radicals, it can readily cross biological membranes and consequently can cause oxidative damage far from the site of its formation. Because $\mathrm{H}_{2} \mathrm{O}_{2}$ is the only ROS that can diffuse through aquaporins in the membranes and over larger distances within the cell [41] and is relatively stable compared to other ROS, it has received particular attention as a signal molecule involved in the regulation of specific biological processes and triggering tolerance against various environmental stresses such as plantpathogen interactions at low concentration $[19,20,42]$. At high concentration, $\mathrm{H}_{2} \mathrm{O}_{2}$ can oxidize the cysteine $(-\mathrm{SH})$ or methionine residues $\left(-\mathrm{SCH}_{3}\right)$, and inactivate enzymes by oxidizing their thiol groups, such as enzymes of Calvin cycle, $\mathrm{Cu} / \mathrm{Zn}-\mathrm{SOD}$, and Fe-SOD [43]. When hydrogen peroxide accumulates at levels of $10 \mu \mathrm{M}$, the enzymes in the Calvin cycle, such as fructose-1,6-bisphosphatase, sedoheptulose1,7-bisphosphatase, and phosphoribulokinase, lose $50 \%$ of their activity [44, 45]. It also oxidizes protein kinases, phosphatases, and transcription factors containing thiolate residues. At high concentrations, it orchestrates programmed cell death [46].

Both $\mathrm{O}_{2}{ }^{-}$and $\mathrm{H}_{2} \mathrm{O}_{2}$ are only moderately reactive. The cellular damage by ROS appears to be due to their conversion into more reactive species. The formation of ${ }^{\bullet} \mathrm{OH}$ is dependent on both $\mathrm{H}_{2} \mathrm{O}_{2}$ and $\mathrm{O}_{2}{ }^{-}$and, thus, its formation is subject to inhibition by both SOD and CAT.

The Haber-Weiss reaction generates ${ }^{\circ} \mathrm{OH}$ from $\mathrm{H}_{2} \mathrm{O}_{2}$ and $\mathrm{O}_{2}{ }^{\bullet-}$. It consists of the following two reactions:

$$
\mathrm{Fe}^{3+}+\mathrm{O}_{2}^{\cdot-} \longrightarrow \mathrm{Fe}^{2+}+\mathrm{O}_{2}
$$

First, $\mathrm{Fe}(\mathrm{III})$ is reduced by $\mathrm{O}_{2}{ }^{\bullet-}$, followed by oxidation by dihydrogen peroxide (Fenton reaction)

$$
\mathrm{Fe}^{2+}+\mathrm{H}_{2} \mathrm{O}_{2} \longrightarrow \mathrm{Fe}^{3+}+\mathrm{OH}^{-}+\cdot \mathrm{OH},
$$

and reaction:

$$
\mathrm{O}_{2}{ }^{--}+\mathrm{H}_{2} \mathrm{O}_{2} \longrightarrow \cdot \mathrm{OH}+\mathrm{OH}^{-}+\mathrm{O}_{2} \text {. }
$$

Metal catalysis is necessary for this reaction since the rate of uncatalyzed reaction is negligible [47]. ${ }^{\bullet} \mathrm{OH}$ is the most reactive among all ROS. It has a single unpaired electron, thus, it can react with oxygen in triplet ground state. ${ }^{\circ} \mathrm{OH}$ interacts with all biological molecules and causes subsequent cellular damages such as lipid peroxidation, protein damage, and membrane destruction [48]. Because cells have no enzymatic mechanism to eliminate ${ }^{\bullet} \mathrm{OH}$, its excess production can eventually lead to cell death [49]. Under illumination, formation of ${ }^{\bullet} \mathrm{OH}$ by the Fenton reaction at the active site of the enzyme RbcL leads to its fragmentation in chloroplast lysates $[50,51]$. The oxidation of organic substrates by ${ }^{\circ} \mathrm{OH}$ may proceed by two possible reactions, either by addition of $\cdot \mathrm{OH}$ to organic molecules or due to abstraction of a hydrogen atom from it. Because of short lifetime and the strongly positive redox potential (close to $+2 \mathrm{~V}$ ) of "free" $\cdot \mathrm{OH}$, its sites of reaction are close to its point of formation [52]. In this context, organic oxygen radicals such as alkoxy, peroxy, semiquinones, reduced hydrogen peroxide, and hydrogen peroxide-electron donor complexes (crypto-OH), as well as metallo-oxygen complexes, have been proposed as the ultimately active species besides destructive free ${ }^{\bullet} \mathrm{OH}$ [53]. 


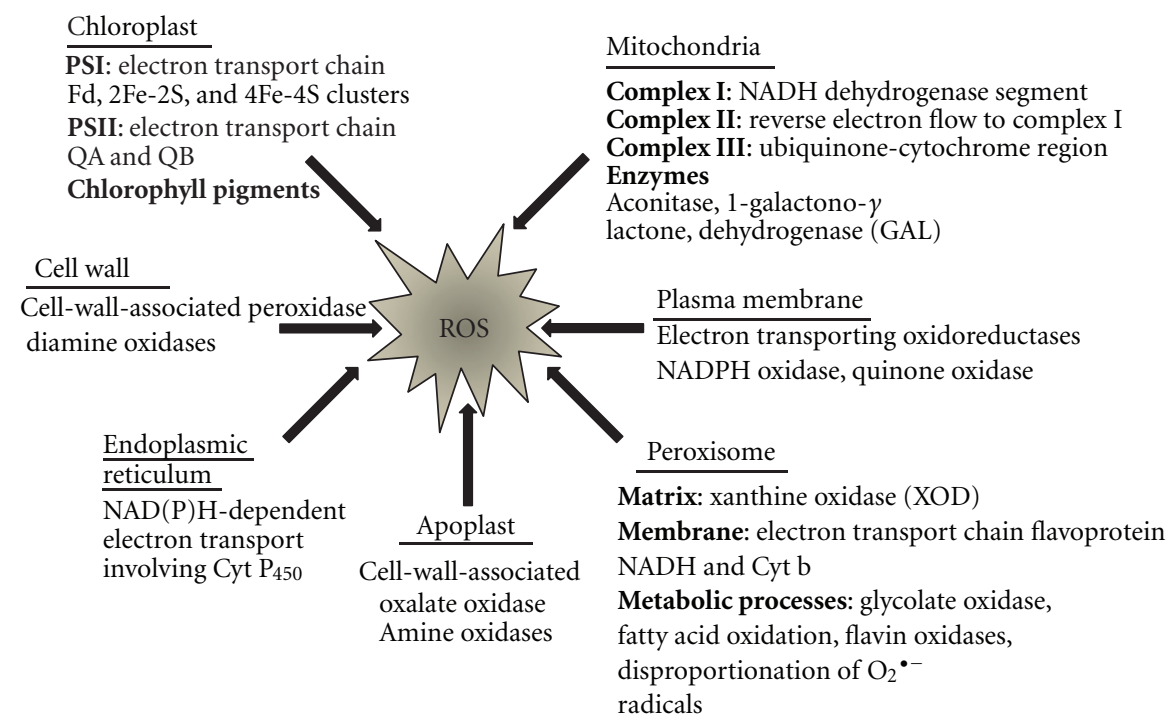

FIGURE 2: Sites of production of reactive oxygen species (ROS) in plants. ROS are produced at several locations in the cell-like chloroplast, mitochondria, plasma membrane, peroxisomes, apoplast, endoplasmic reticulum, and cell wall.

2.2. Sites of Production of ROS. ROS are produced in both unstressed and stressed cells at several locations in chloroplasts, mitochondria, plasma membranes, peroxisomes, apoplast, endoplasmic reticulum, and cell walls (Figure 2). ROS are always formed by the inevitable leakage of electrons onto $\mathrm{O}_{2}$ from the electron transport activities of chloroplasts, mitochondria, and plasma membranes or as a byproduct of various metabolic pathways localized in different cellular compartments.

2.2.1. Chloroplasts. In chloroplasts, various forms of ROS are generated from several locations. ETCs in PSI and PSII are the main sources of ROS in chloroplasts. Production of ROS by these sources is enhanced in plants by conditions limiting $\mathrm{CO}_{2}$ fixation, such as drought, salt, and temperature stresses, as well as by the combination of these conditions with high-light stress. Under normal conditions, the electron flow from the excited PS centers to NADP which is reduced to NADPH which, then, enters the Calvin cycle and reduces the final electron acceptor, $\mathrm{CO}_{2}$. In case of overloading of the ETC, due to decreased NADP supply resulting from stress conditions, there is leakage of electron from ferredoxin to $\mathrm{O}_{2}$, reducing it to $\mathrm{O}_{2}{ }^{--}$[54]. This process is called Mehler reaction:

$$
2 \mathrm{O}_{2}+2 \mathrm{Fd}_{\mathrm{red}} \longrightarrow 2 \mathrm{O}_{2}^{\bullet-}+2 \mathrm{Fd}_{\mathrm{ox}}
$$

Leakage of electrons to $\mathrm{O}_{2}$ may also occur from $2 \mathrm{Fe}-2 \mathrm{~S}$ and $4 \mathrm{Fe}-4 \mathrm{~S}$ clusters in the ETC of PSI. In PSII, acceptor side of ETC contains QA and QB. Leakage of electron from this site to $\mathrm{O}_{2}$ contributes to the production of $\mathrm{O}_{2}{ }^{\bullet-}$ [55].

The formation of $\mathrm{O}_{2}{ }^{--}$by $\mathrm{O}_{2}$ reduction is a rate-limiting step. Once formed $\mathrm{O}_{2}{ }^{\bullet-}$ generates more aggressive ROS. It may be protonated to $\mathrm{HO}_{2}{ }^{\circ}$ on the internal, "lumen" membrane surface or dismutated enzymatically (by SOD) or spontaneously to $\mathrm{H}_{2} \mathrm{O}_{2}$ on the external "stromal" membrane surface. At Fe-S centers where $\mathrm{Fe}^{2+}$ is available, $\mathrm{H}_{2} \mathrm{O}_{2}$ may be transformed through the Fenton reaction into the much more dangerous $\mathrm{OH}^{\bullet}$.

2.2.2. Mitochondria. Mitochondria can produce ROS in several sites of ETC. In mitochondria direct reduction of oxygen to $\mathrm{O}_{2}{ }^{--}$occurs in the flavoprotein region of NADH dehydrogenase segment (complex I) of the respiratory chain [56]. When $\mathrm{NAD}^{+}$-linked substrates for complex I are limited, electron transport can occur from complex II to complex I (reverse electron flow). This process has been shown to increase ROS production at complex I and is regulated by ATP hydrolysis [57]. Ubiquinone-cytochrome region (complex III) of the ETC also produces $\mathrm{O}_{2}{ }^{--}$from oxygen. It is believed that fully reduced ubiquinone donates an electron to cytochrome $\mathrm{C}_{1}$ and leaves an unstable highly reducing ubisemiquinone radical which is favorable for the electron leakage to $\mathrm{O}_{2}$ and, hence, to $\mathrm{O}_{2}{ }^{--}$formation [58]. In plants, under normal aerobic conditions, ETC and ATP syntheses are tightly coupled; however, various stress factors lead to inhibition and modification of its component, leading to over reduction of electron carriers and, hence, formation of $\operatorname{ROS}[4,59]$.

Several enzymes present in mitochondrial matrix can produce ROS. Some of them produce ROS directly, for example aconitase, whereas some others like 1-galactono$\gamma$ lactone dehydrogenase (GAL), are able to feed electrons to ETC $[60,61] . \mathrm{O}_{2}{ }^{--}$is the primary ROS formed by monovalent reduction in the ETC. It is converted quickly either by the MnSOD (mitochondrial form of SOD) or APX into the relatively stable and membrane-permeable $\mathrm{H}_{2} \mathrm{O}_{2}$. $\mathrm{H}_{2} \mathrm{O}_{2}$ can be further converted to extremely active hydroxyl radical $\left(\mathrm{OH}^{\bullet}\right)$ in the Fenton reaction. 
2.2.3. Endoplasmic Reticulum. In endoplasmic reticulum, $\mathrm{NAD}(\mathrm{P}) \mathrm{H}$-dependent electron transport involving Cyt $\mathrm{P}_{450}$ produces $\mathrm{O}_{2}{ }^{--}$[7]. Organic substrate, $\mathrm{RH}$, reacts first with Cyt $\mathrm{P}_{450}$ and then is reduced by a flavoprotein to form a radical intermediate $\left(\mathrm{Cyt}_{4} \mathrm{P}_{40} \mathrm{R}^{-}\right)$. Triplet oxygen can readily react with this radical intermediate as each has one unpaired electron. This oxygenated complex $\left(\mathrm{Cyt} \mathrm{P}_{450}-\mathrm{ROO}^{-}\right)$may be reduced by cytochrome $\mathrm{b}$ or occasionally the complexes may decompose releasing $\mathrm{O}_{2}{ }^{\cdot-}$.

2.2.4. Peroxisomes. Peroxisomes are probably the major sites of intracellular $\mathrm{H}_{2} \mathrm{O}_{2}$ production, as a result of their essentially oxidative type of metabolism [3]. The main metabolic processes responsible for the generation of $\mathrm{H}_{2} \mathrm{O}_{2}$ in different types of peroxisomes are the glycolate oxidase reaction, the fatty acid $\beta$-oxidation, the enzymatic reaction of flavin oxidases, and the disproportionation of $\mathrm{O}_{2}{ }^{--}$radicals [62]. During photorespiration, the oxidation of glycolate by glycolate oxidase in peroxisomes accounts for the majority of $\mathrm{H}_{2} \mathrm{O}_{2}$ production [63]. Like mitochondria and chloroplasts, peroxisomes also produce $\mathrm{O}_{2}{ }^{\bullet-}$ as a consequence of their normal metabolism. In peroxisomes from pea leaves and watermelon cotyledons, at least, two sites of $\mathrm{O}_{2}{ }^{\bullet-}$ generation have been identified using biochemical and electron spin resonance spectroscopy (ESR) methods: one in the organelle matrix, the generating system being XOD, which catalyses the oxidation of xanthine or hypoxanthine to uric acid, and produces $\mathrm{O}_{2}{ }^{--}$in the process and another site in the peroxisomal membranes where a small ETC composed of a flavoprotein NADH and Cyt b is involved. Three integral peroxisomal membrane polypeptides (PMPs) with molecular masses of 18,29 , and $32 \mathrm{kDa}$ were found to be involved in $\mathrm{O}_{2}{ }^{-}$production. While the 18 - and $32-\mathrm{kDa}$ PMPs use NADH as electron donor for $\mathrm{O}_{2}{ }^{-}$- production, the 29-kDa PMP was clearly dependent on NADPH and was able to reduce cytochrome $\mathrm{c}$ with NADPH as electron donor [64]. Among the three integral polypeptides, the main producer of $\mathrm{O}_{2}{ }^{--}$was the 18 -kDa PMP which was proposed to be a cytochrome possibly belonging to the b-type group. The PMP32 very probably corresponds to the MDHAR, and the third $\mathrm{O}_{2}{ }^{-}$-generating polypeptide, PMP29, could be related to the peroxisomal NADPH:cytochrome P450 reductase [64]. The $\mathrm{O}_{2}^{\cdot-}$ produced is subsequently converted into $\mathrm{H}_{2} \mathrm{O}_{2}$ by SOD.

2.2.5. Plasma Membranes. Electron transporting oxidoreductases are ubiquitous at plasma membranes and lead to generation of ROS at plasma membrane. Production of ROS was studied using EPR spin-trapping techniques and specific dyes in isolated plasma membranes from the growing and the nongrowing zones of hypocotyls and roots of etiolated soybean seedlings as well as coleoptiles and roots of etiolated maize seedlings [5]. $\mathrm{NAD}(\mathrm{P}) \mathrm{H}$ mediated the production of $\mathrm{O}_{2}{ }^{-{ }^{-}}$in all plasma membrane samples. It was suggested that in soybean plasma membranes, $\mathrm{O}_{2}{ }^{--}$production could be attributed to the action of at least two enzymes, an NADPH oxidase, and, in the presence of menadione, a quinone reductase [5]. NADPH oxidase catalyses transfer of electrons from cytoplasmic NADPH to $\mathrm{O}_{2}$ to form $\mathrm{O}_{2}{ }^{\bullet-} \cdot \mathrm{O}_{2}{ }^{\bullet-}$ is dismutated to $\mathrm{H}_{2} \mathrm{O}_{2}$ either spontaneously or by SOD activity. NADPH oxidase has been proposed to play a key role in the production and accumulation of ROS in plants under stress conditions $[28,42,65]$.

2.2.6. Cell Walls. Cell walls are also regarded as active sites for ROS production. Role of cell-wall-associated peroxidase in $\mathrm{H}_{2} \mathrm{O}_{2}$ generation has been shown. In horseradish, peroxidase associated with isolated cell walls catalyzes the formation of $\mathrm{H}_{2} \mathrm{O}_{2}$ in the presence of NADH. The reaction is stimulated by various monophenols, especially of coniferyl alcohol. Malate dehydrogenase was found to be the sole candidate for providing NADH [66]. The generation of ROS by cell-walllocated peroxidases has been shown during hypersensitive response (HR) triggered in cotton by the bacterium Xanthomonas campestris pv. malvacearum [67] and potassium (K) deficiency stress in Arabidopsis [68]. Diamine oxidases are also involved in production of activated oxygen in the cell wall using diamine or polyamines (putrescine, spermidine, cadaverine, etc.) to reduce a quinone that autooxidizes to form peroxides [54].

2.2.7. Apoplast. Cell-wall-located enzymes have been proved to be responsible for apoplastic ROS production $[5,28]$. The cell-wall-associated oxalate oxidase, also known as germin, releases $\mathrm{H}_{2} \mathrm{O}_{2}$ and $\mathrm{CO}_{2}$ from oxalic acid [69]. This enzyme was reported to be involved in apoplastic hydrogen peroxide accumulation during interactions between different cereals species and fungi [70]. Amine oxidase-like enzymes may contribute to defense responses occurring in the apoplast following biotic stress, mainly through $\mathrm{H}_{2} \mathrm{O}_{2}$ production [71]. Amine oxidases catalyze the oxidative deamination of polyamines (i.e., putrescine, spermine, and spermidine) using FAD as a cofactor [71]. Heyno and coworkers [5], based on their study, concluded that apoplastic $\mathrm{OH}^{\bullet}$ generation depends fully, or for the most part, on peroxidase localized in the cell wall.

2.3. Role of ROS as Messengers. At low/moderate concentration, ROS have been implicated as second messengers in intracellular signaling cascades that mediate several plant responses in plant cells, including stomatal closure $[19,20$, $65]$, programmed cell death $[7,72]$, gravitropism [73], and acquisition of tolerance to both biotic and abiotic stresses $[42,74]$. Figure 3 shows the role of ROS as second messenger in hormone mediated cellular responses in plants. Plants can sense, transduce and translate ROS signal into appropriate cellular responses with the help of some redox-sensitive proteins, calcium mobilization, protein phosphorylation, and gene expression. ROS can be sensed directly also by key signaling proteins such as a tyrosine phosphatase through oxidation of conserved cysteine residues (reviewed in [75]). ROS can also modulate the activities of many components in signaling, such as protein phosphatases, protein kinases and transcription factors [76] and communicate with other signal molecules and the pathway forming part of the signaling network that controls response downstream of ROS 


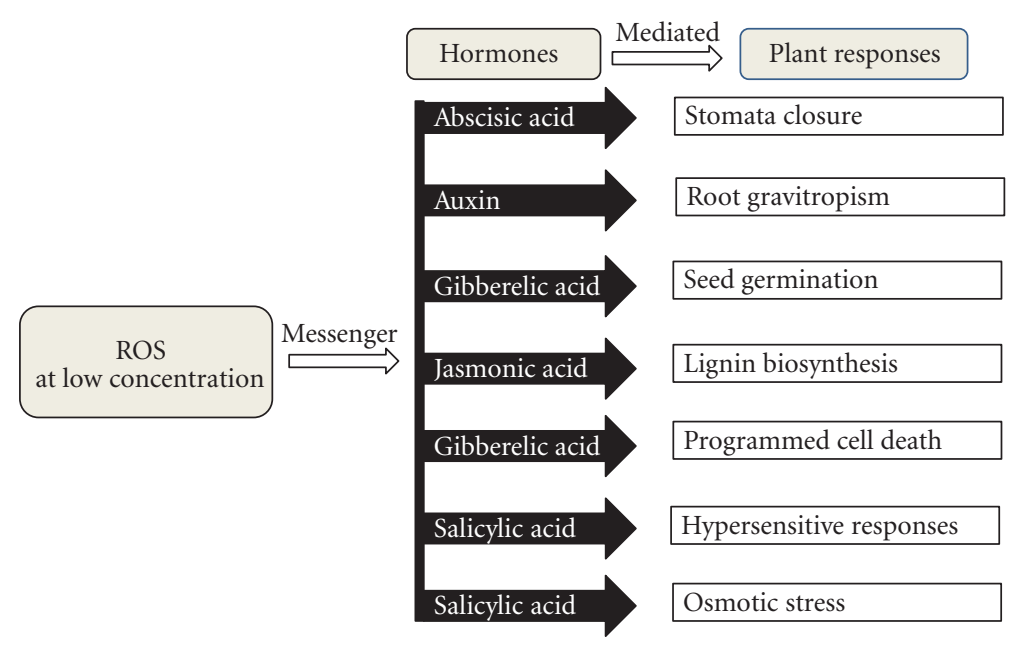

FIGURE 3: Reactive oxygen species (ROS) as second messengers in several plant hormone responses, including stomatal closure, root gravitropism, seed germination, lignin biosynthesis, programmed cell death, hypersensitive responses, and osmotic stress.

[19]. The strength, lifetime and size of the ROS signaling pool depends on balance between oxidant production and removal by the antioxidant. Using mutants deficient in key ROS-scavenging enzymes, Miller and coworkers [74] identified a signaling pathway that is activated in cells in response to ROS accumulation. Interestingly, many of the key players in this pathway, including different zinc finger proteins and WRKY transcription factors, are also central regulators of abiotic stress responses involved in temperature, salinity and osmotic stresses.

ROS are considered second messengers in the abscisic acid (ABA) transduction pathway in guard cells [19, 20]. ABA induced $\mathrm{H}_{2} \mathrm{O}_{2}$ is an essential signal in mediating stomatal closure to reduce water loss through the activation of calcium-permeable channels in the plasma membrane [77]. Jannat and coworkers [78] observed that ABAinducible cytosolic $\mathrm{H}_{2} \mathrm{O}_{2}$ elevation functions in ABAinduced stomatal closure, while constitutive increase of $\mathrm{H}_{2} \mathrm{O}_{2}$ does not cause stomatal closure. Role of ROS as second messenger in root gravitropism has been demonstrated. Based on their work, Joo and coworkers [73] proposed that gravity induces asymmetric movement of auxin within $60 \mathrm{~min}$, and, then, the auxin stimulates ROS generation to mediate gravitropism. Further, scavenging of ROS by antioxidants ( $\mathrm{N}$-acetylcysteine, ascorbic acid, and Trolox) inhibited root gravitropism [73]. ROS appear to be involved in dormancy alleviation. In dormant barley grains under control condition, gibberellic acid (GA) signaling and ROS content are low, while ABA signaling is high, resulting in dormancy. Exogenous $\mathrm{H}_{2} \mathrm{O}_{2}$ does not appear to alter ABA biosynthesis and signaling, but has a more pronounced effect on GA signaling, inducing a change in hormonal balance that results in germination [79]. ROS have been shown to play a key role in PCD in barley aleurone cells, initiated by GA. Bethke and Jones [72] observed that GA-treated aleurone protoplasts are less tolerant to internally generated or exogenously applied $\mathrm{H}_{2} \mathrm{O}$ than ABA-treated protoplasts and suggested that ROS are components of the hormonally regulated cell death pathway in barley aleurone cells.

Plants have evolved a complex regulatory network to mediate biotic and abiotic stress responses based on ROS synthesis, scavenging, and signaling. Transient production of ROS is detected in the early events of plant-pathogen interactions and plays an important signaling role in pathogenesis signal transduction regulators. This production-called oxidative burst could be considered as a specific signal during the interaction process [80]. In HR, SA is thought to potentiate ROS signaling [81]. ROS are shown to act as a second messenger for the induction of defense genes in tomato plants in response to wounding [82]. ROS were generated near cell walls of vascular bundle cells of tomato leaves in response to wounding and resulted $\mathrm{H}_{2} \mathrm{O}_{2}$ from woundinducible polygalacturonase acted as a second messenger for the activation of defense genes in mesophyll cells, but not for signaling pathway genes in vascular bundle cells [82].

Lignin is important for the plant's response to environmental stress. Denness and coworkers [83] characterized a genetic network enabling plants to regulate lignin biosynthesis in response to cell wall damage through dynamic interactions between Jasmonic acid and ROS. ROS have been shown to play important roles in osmotic stress, low temperature, and heavy metal signal transduction pathway [75, 84, 85]. Genes involved in osmotic stress signaling have been shown to be upregulated by ROS, including the transcription factor $D R E B 2 A$ and a histidine kinase [18]. In Arabidopsis culture cells, it was reported that the MAPK AtMPK6 that can be activated by low temperature and osmotic stress could also be activated by oxidative stress [84]. Borsani and coworkers [86] suggested that the increased osmotic stress tolerance of transgenic Arabidopsis expressing a salicylate hydroxylase (NahG) gene, might result from decreased SA-mediated ROS generation. Zhao and coworkers [87] reported that ROS play important roles in drought-induced abscisic acid synthesis in plant and suggested that they may be the signals through 


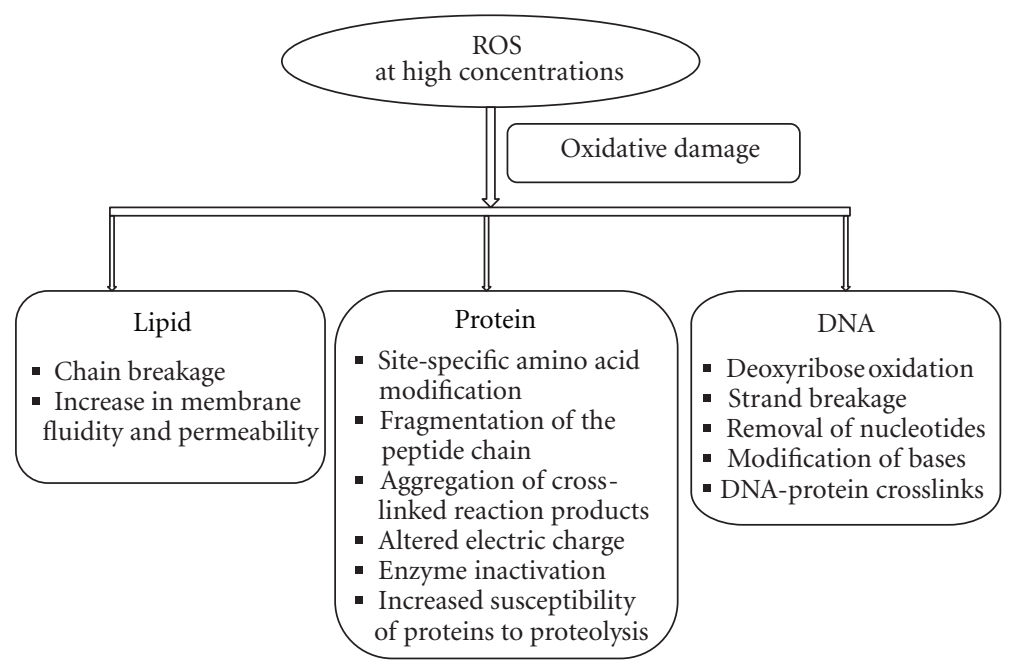

FIgURE 4: Reactive oxygen species (ROS) induced oxidative damage to lipids, proteins, and DNA.

which the plant can "sense" the drought condition. Using pharmacological inhibitors, it is demonstrated that metals $\mathrm{Cd}^{2+}$ and $\mathrm{Cu}^{2+}$ induce MAP kinase activation via distinct ROS-generating systems [85].

2.4. ROS and Oxidative Damage to Biomolecules. Production and removal of ROS must be strictly controlled in order to avoid oxidative stress. When the level of ROS exceeds the defense mechanisms, a cell is said to be in a state of "oxidative stress". However, the equilibrium between production and scavenging of ROS is perturbed under a number of stressful conditions such as salinity, drought, high light, toxicity due to metals, pathogens, and so forth. Enhanced level of ROS can cause damage to biomolecules such as lipids, proteins and DNA (Figure 4). These reactions can alter intrinsic membrane properties like fluidity, ion transport, loss of enzyme activity, protein cross-linking, inhibition of protein synthesis, DNA damage, and so forth ultimately resulting in cell death.

2.4.1. Lipids. When ROS level reaches above threshold, enhanced lipid peroxidation takes place in both cellular and organellar membranes, which, in turn, affect normal cellular functioning. Lipid peroxidation aggravates the oxidative stress through production of lipid-derived radicals that themselves can react with and damage proteins and DNA. The level of lipid peroxidation has been widely used as an indicator of ROS mediated damage to cell membranes under stressful conditions. Increased peroxidation (degradation) of lipids has been reported in plants growing under environmental stresses $[8,10,12,13]$. Increase in lipid peroxidation under these stresses parallels with increased production of ROS. Malondialdehyde (MDA) is one of the final products of peroxidation of unsaturated fatty acids in phospholipids and is responsible for cell membrane damage [43]. Two common sites of ROS attack on the phospholipid molecules are the unsaturated (double) bond between two carbon atoms and the ester linkage between glycerol and the fatty acid. The polyunsaturated fatty acids (PUFAs) present in membrane phospholipids are particularly sensitive to attack by ROS. A single $\cdot \mathrm{OH}$ can result in peroxidation of many polyunsaturated fatty acids because the reactions involved in this process are part of a cyclic chain reaction. The overall process of lipid peroxidation involves three distinct stages: initiation, progression, and termination steps. The initial phase of lipid peroxidation includes activation of $\mathrm{O}_{2}$ which is rate limiting. $\mathrm{O}_{2}{ }^{-}$and ${ }^{\bullet} \mathrm{OH}$ can react with methylene groups of PUFA forming conjugated dienes, lipid peroxy radicals and hydroperoxides [88]:

$$
\begin{gathered}
\text { PUFA }-\mathrm{H}+\mathrm{X}^{\bullet} \longrightarrow \mathrm{PUFA}+\mathrm{X}-\mathrm{H} . \\
\text { PUFA }+\mathrm{O}_{2} \longrightarrow \text { PUFA - OO }{ }^{\bullet} .
\end{gathered}
$$

The peroxy radical formed is highly reactive and able to propagate the chain reaction:

$$
\mathrm{PUFA}-\mathrm{OO}^{\bullet}+\mathrm{PUFA}-\mathrm{OOH} \longrightarrow \mathrm{PUFA}-\mathrm{OOH}+\mathrm{PUFA}^{\bullet}
$$

The formation of conjugated diene occurs when free radicals attack the hydrogens of methylene groups separating double bonds and, thereby, rearrangement of the bonds occurs [89]. The lipid hydroperoxides produced (PUFA-OOH) can undergo reductive cleavage by reduced metals, such as $\mathrm{Fe}^{2+}$, according to the following reaction:

$$
\begin{aligned}
\mathrm{Fe}^{2+} & \text { complex }+ \text { PUFA }-\mathrm{OOH} \\
& \longrightarrow \mathrm{Fe}^{3+} \text { complex + PUFA }-\mathrm{O}^{\bullet}
\end{aligned}
$$

Several reactive species including: lipid alkoxyl radicals, aldehydes (malonyldialdehyde, acrolein and crotonaldehyde), alkanes, lipid epoxides, and alcohols can be easily formed by the decomposition of lipid hydroperoxide [90]. The lipid alkoxy radical produced, (PUFA-O ${ }^{\bullet}$ ), can initiate additional chain reactions [91]:

$$
\mathrm{PUFA}-\mathrm{O}^{\bullet}+\mathrm{PUFA}-\mathrm{H} \longrightarrow \mathrm{PUFA}-\mathrm{OH}+\mathrm{PUFA}^{\bullet}
$$


Peroxidation of polyunsaturated fatty acid by ROS attack can lead to chain breakage and, thereby, increase in membrane fluidity and permeability.

2.4.2. Proteins. The attack of ROS on proteins may cause modification of proteins in a variety of ways, some are direct and others indirect. Direct modification involves modulation of a protein's activity through nitrosylation, carbonylation, disulphide bond formation, and glutathionylation. Proteins can be modified indirectly by conjugation with breakdown products of fatty acid peroxidation [92]. As a consequence of excessive ROS production, site-specific amino acid modification, fragmentation of the peptide chain, aggregation of cross-linked reaction products, altered electric charge and increased susceptibility of proteins to proteolysis occur. Tissues injured by oxidative stress generally contain increased concentrations of carbonylated proteins which is widely used marker of protein oxidation [93]. Enhanced modification of proteins has been reported in plants under various stresses $[8,11,12,94]$. The amino acids in a peptide differ in their susceptibility to attack by ROS. Thiol groups and sulphur containing amino acids are very susceptible sites for attack by ROS. Activated oxygen can abstract an $\mathrm{H}$ atom from cysteine residues to form a thiyl radical that will cross-link to second thiyl radical to form disulphide bridge. Several metals, including $\mathrm{Cd}, \mathrm{Pb}$, and $\mathrm{Hg}$ have been shown to cause the depletion of protein bound thiol groups [95]. Oxygen also can be added to a methionine to form methionine sulphoxide derivative [96]. Tyrosine is readily cross-linked to form bityrosine products in the presence of ROS [97].

Oxidation of iron-sulphur centers by $\mathrm{O}_{2}{ }^{--}$is irreversible and leads to enzyme inactivation [98]. In these cases, the metal $(\mathrm{Fe})$ binds to a divalent cation-binding site on the protein. The metal $(\mathrm{Fe})$, then, reacts in a Fenton reaction to form a ${ }^{\bullet} \mathrm{OH}$ that rapidly oxidizes an amino acid residue at or near the cation-binding site of the protein [99]. Oxidized proteins serve as better substrates for proteolytic digestion. It has been suggested that protein oxidation could predispose it to ubiquitination, which, in turn, would be a target for proteasomal degradation [100]. The incubation of pea leaf crude extracts with increasing $\mathrm{H}_{2} \mathrm{O}_{2}$ concentrations, Cdtreated plants and peroxisomes purified from pea leaves showed increase in carbonyl content. Oxidized proteins were more efficiently degraded, and the proteolytic activity increased $20 \%$ due to the metal treatment [94]. Several studies have revealed that after a certain degree further damage leads to extensively cross-linked and aggregated products, which are not only poor substrates for degradation, but also can inhibit proteases to degrade other oxidized proteins [101].

2.4.3. DNA. ROS are a major source of DNA damage [102]. ROS can cause oxidative damages to nuclear, mitochondrial, and chloroplastic DNA. DNA is cell's genetic material and any damage to the DNA can result in changes in the encoded proteins, which may lead to malfunctions or complete inactivation of the encoded proteins. Oxidative attack on DNA results in deoxyribose oxidation, strand breakage, removal of nucleotides, variety of modifications in the organic bases of the nucleotides, and DNA-protein crosslinks. Further, changes in the nucleotides of one strand can result in the mismatches with the nucleotides in the other strand, yielding subsequent mutations. Enhanced DNA degradation has been observed in plants exposed to various environmental stresses such as salinity [103] and metal toxicity [17]. Both the sugar and base moieties of DNA are susceptible to oxidation by ROS. Oxidative attack to DNA bases generally involves - $\mathrm{OH}$ addition to double bonds, while sugar damage mainly results from hydrogen abstraction from deoxyribose [104]. The hydroxyl radical is known to react with all purine and pyrimidine bases and, also, the deoxyribose backbone [105]. - OH generates various products from the DNA bases which mainly include C-8 hydroxylation of guanine to form 8oxo-7,8 dehydro- $2^{\prime}$ - deoxyguanosine, hydroxymethyl urea, urea, thymine glycol, thymine and adenine ring-opened, and saturated products [106]. 8-Hydroxyguanine is the most commonly observed product. ${ }^{1} \mathrm{O}_{2}$ only reacts with guanine, whereas $\mathrm{H}_{2} \mathrm{O}_{2}$ and $\mathrm{O}_{2}{ }^{\bullet-}$ do not react with bases at all $[104,107]$. ROS-induced DNA damages include various mutagenic alterations as well. For example, mutation arising from selective modification of G:C sites, especially, indicates oxidative attack on DNA by ROS. ROS attack DNA bases indirectly through reactive products generated by ROS attack to other macromolecules such as lipid [108].

ROS attack to DNA sugars leads to single-strand breaks. ROS abstract hydrogen atom from the $\mathrm{C}^{\prime}$ position of deoxyribose, leading to generation of a deoxyribose radical that further reacts to produce DNA strand breakage [109]. Under physiological conditions, neither $\mathrm{H}_{2} \mathrm{O}_{2}$ alone nor $\mathrm{O}_{2}{ }^{--}$can cause in vitro strand breakage. Therefore, it was concluded that the toxicity associated with these ROS in vivo is most likely the result of Fenton reaction. When ${ }^{\bullet} \mathrm{OH}$ attacks on either DNA or proteins associated with it, DNA protein crosslinks are formed [110]. DNA protein crosslinks cannot be readily repaired and may be lethal if replication or transcription precedes repair. Mitochondrial and chloroplast DNA are more susceptible to oxidative damage than nuclear DNA due to the lack of protective protein, histones, and close locations to the ROS producing systems in the former [111]. Even though repair system exists for damaged DNA, excessive changes caused by ROS lead to permanent damage to the DNA with potentially detrimental effects for the cell.

\section{Antioxidative Defense System in Plants}

Plants possess complex antioxidative defense system comprising of nonenzymatic and enzymatic components to scavenge ROS. In plant cells, specific ROS producing and scavenging systems are found in different organelles such as chloroplasts, mitochondria, and peroxisomes. ROS scavenging pathways from different cellular compartments are coordinated [112]. Under normal conditions, potentially toxic oxygen metabolites are generated at a low level and there is an appropriate balance between production and quenching of ROS. The balance between production and quenching of ROS may be perturbed by a number of adverse 
environmental factors, giving rise to rapid increases in intracellular ROS levels $[63,113]$, which can induce oxidative damage to lipids, proteins, and nucleic acids. In order to avoid the oxidative damage, higher plants raise the level of endogenous antioxidant defense [113]. Various components of antioxidative defense system involved in ROS scavenging have been manipulated, overexpressed or downregulated to add to the present knowledge and understanding the role of the antioxidant systems.

\subsection{Nonenzymatic Components of Antioxidative Defense Sys-} tem. Nonenzymic components of the antioxidative defense system include the major cellular redox buffers ascorbate (AsA) and glutathione ( $\gamma$-glutamyl-cysteinyl-glycine, GSH) as well as tocopherol, carotenoids, and phenolic compounds. They interact with numerous cellular components and in addition to crucial roles in defense and as enzyme cofactors, these antioxidants influence plant growth and development by modulating processes from mitosis and cell elongation to senescence and cell death [114]. Mutants with decreased nonenzymic antioxidant contents have been shown to be hypersensitive to stress $[115,116]$.

3.1.1. Ascorbate. Ascorbate (AsA) is the most abundant, low molecular weight antioxidant that has a key role in defense against oxidative stress caused by enhanced level of ROS. AsA is considered powerful antioxidant because of its ability to donate electrons in a number of enzymatic and nonenzymatic reactions. AsA has been shown to play important role in several physiological processes in plants, including growth, differentiation, and metabolism. The majority of the AsA pool in plants is contributed by $\mathrm{D}$-mannose/L-galactose commonly called Smirnoff-Wheeler pathway which proceeds via GDP-D-mannose, GDP-L- galactose, L-galactose, and L-galactono-1,4-lactone [117]. AsA is also synthesized via uronic acid intermediates, such as $\mathrm{D}$-galacturonic acid [118]. In this pathway D-galacturonic acid is reduced to L-galactonic acid by galacturonic acid reductase, which is subsequently converted to L-galactono-1,4-lactone. The L-galactono-1,4-lactone is further oxidized to AsA by Lgalactono-1,4-lactone dehydrogenase (GALDH) enzyme. It is synthesized in the mitochondria by L-galactono- $\gamma$-lactone dehydrogenase and is transported to the other cell components through a proton-electrochemical gradient or through facilitated diffusion. It is detected in the majority of plant cell types, organelles and apoplast in plants [119] and is found to be particularly abundant in photosynthetic tissues [120]. Most of AsA, almost more than 90\%, is localized in cytoplasm, but unlike other soluble antioxidants a substantial portion is exported to the apoplast, where it is present in millimolar concentration. Apoplastic AsA is believed to represent the first line of defense against potentially damaging external oxidants [121]. AsA protects critical macromolecules from oxidative damage. Under normal physiological condition, AsA mostly exists in reduced state in chloroplast where it also acts as a cofactor of violaxanthin de-epoxidase, thus, sustaining dissipation of excess excitation energy [122]. It provides membrane protection by directly reacting with $\mathrm{O}_{2}{ }^{--}, \mathrm{H}_{2} \mathrm{O}_{2}$ and regenerating $\alpha$-tocopherol from tocopheroxyl radical and preserves the activities of the enzymes that contain prosthetic transition metal ions [21]. AsA has a key role in removal of $\mathrm{H}_{2} \mathrm{O}_{2}$ via AsAGSH cycle [49]. Oxidation of AsA occurs in two sequential steps, first producing monodehydroascorbate (MDHA) and subsequently dehydroascorbate (DHA). In the AsA-GSH cycle, two molecules of AsA are utilized by APX to reduce $\mathrm{H}_{2} \mathrm{O}_{2}$ to water with concomitant generation of MDHA. MDHA is a radical with a short life time and can spontaneously dismutate into DHA and AsA or is reduced to AsA by $\operatorname{NADP}(\mathrm{H})$ dependent enzyme MDHAR [123]. DHA is also highly unstable at $\mathrm{pH}$ values greater than 6.0 and is decomposed to tartarate and oxalate [21]. To prevent this, DHA is rapidly reduced to AsA by the enzyme DHAR using reducing equivalents from GSH [124].

AsA level has been reported to alter in response to various stresses $[8,11,13,14,125,126]$. The level of AsA under environmental stresses depends on the balance between the rates and capacity of AsA biosynthesis and turnover related to antioxidant demand [127]. Overexpression of enzymes involved in AsA biosynthesis confers abiotic stress tolerance in plants. GDP-Mannose $3^{\prime}, 5^{\prime}$-epimerase (GME) catalyses the conversion of GDP-D-mannose to GDP-L-galactose, an important step in the Smirnoff-Wheeler pathway of AsA biosynthesis in higher plants. Overexpression of two members of the GME gene family resulted in increased accumulation of ascorbate and improved tolerance to abiotic stresses in tomato plants [128]. Overexpression of strawberry $\mathrm{D}$-galacturonic acid reductase which participates in AsA biosynthetic pathway involving D-galacturonic acid as intermediate and reduces D-galacturonic acid to L-galactonic acid, leads to accumulation of AsA and enhanced abiotic stress tolerance in potato plants [129]. Increased AsA content has been shown to confer oxidative stress tolerance in Arabidopsis [130]. The $v t c-1$ mutant, deficient in the activity of GDP-mannose pyrophosphorylase, an enzyme found in the initial part of the ascorbate biosynthetic pathway before it becomes committed to ascorbate synthesis [117] was found to be more sensitive to supplementary UV-B treatment than wild type plants [115].

3.1.2. Glutathione. Tripeptide glutathione ( $\gamma$-glutamylcysteinyl-glycine, GSH) is one of the crucial low molecular weight nonprotein thiol that plays an important role in intracellular defense against ROS-induced oxidative damage. It has been detected virtually in all cell compartments such as cytosol, chloroplasts, endoplasmic reticulum, vacuoles, and mitochondria [131]. GSH is synthesized in the cytosol and chloroplasts of plant cells by compartment specific isoforms of $\gamma$-glutamyl-cysteinyl synthetase $(\gamma$-ECS) and glutathione synthetase (GS). The balance between the GSH and glutathione disulfide (GSSG) is a central component in maintaining cellular redox state. Due to its reducing power, GSH plays an important role in diverse biological processes, including cell growth/division, regulation of sulfate transport, signal transduction, conjugation of metabolites, enzymatic regulation, synthesis of proteins and nucleic acids, 
synthesis of phytochelatins for metal chelation, detoxification of xenobiotics, and the expression of the stressresponsive genes [48]. GSH functions as an antioxidant in many ways. It can react chemically with $\mathrm{O}_{2}{ }^{\bullet-}, \cdot \mathrm{OH}, \mathrm{H}_{2} \mathrm{O}_{2}$ and, therefore, can function directly as a free radical scavenger. GSH can protect macromolecules (i.e., proteins, lipids, DNA) either by the formation of adducts directly with reactive electrophiles (glutathiolation) or by acting as proton donor in the presence of ROS or organic free radicals, yielding GSSG [132]. It can participate in regeneration of another potential antioxidant AsA, via the AsA-GSH cycle. GSH recycles AsA from it's oxidized to reduced form by the enzyme DHAR [133]. GSH can also reduce DHA by a nonenzymic mechanism at $\mathrm{pH}>7$ and at GSH concentrations greater than $1 \mathrm{mM}$. This may be a significant pathway in chloroplasts, where in the presence of light, $\mathrm{pH}$ remains around 8 and GSH concentration may be as high as $5 \mathrm{mM}$ [134]. Generation and maintenance of reduced GSH pool, either by de novo synthesis or via recycling by GR, using NADPH as a cofactor and electron donor, is of vital importance for the cell. The role of GSH in the antioxidative defense system provides a rationale for its use as a stress marker. When apple trees were subjected to progressive drought, the initial response was a little oxidation of the GSH pool, followed by increased GSH concentrations. When the stress increased, GSH concentrations dropped and redox state became more oxidized, which marked the degradation of the system [135]. Similar to drought stress, altered ratio of GSH/GSSG has been observed in plants under various stresses like salinity [136], chilling [126], and metal toxicity $[11,13-15]$. Overexpression of enzyme glutathione synthetase involved in GSH biosynthesis showed no effect on GSH level and was not sufficient to improve ozone tolerance [137] and resistance to photoinhibition [138] in hybrid poplar (Populus tremula $\times$ P. alba). However, overexpression of $\gamma$-ECS showed reduced sensitivity towards cadmium stress in Indian mustard [139] and enhanced tolerance towards chloroacetanilide herbicides in poplar plants [140]. Eltayeb and coworkers [141] observed greater protection against oxidative damages imposed by various environmental stresses in transgenic potato with higher level of reduced glutathione.

3.1.3. Tocopherols. Tocopherols $(\alpha, \beta, \gamma$, and $\delta)$ represent a group of lipophilic antioxidants involved in scavenging of oxygen free radicals, lipid peroxy radicals, and ${ }^{1} \mathrm{O}_{2}$ [142]. Relative antioxidant activity of the tocopherol isomers in vivo is $\alpha>\beta>\gamma>\delta$ which is due to the methylation pattern and the amount of methyl groups attached to the phenolic ring of the polar head structure [143]. Hence, $\alpha$-tocopherol with its three methyl substituents has the highest antioxidant activity of tocopherols [144]. Tocopherols are synthesized only by photosynthetic organisms and are present in only green parts of plants. The tocopherol biosynthetic pathway utilizes two compounds homogentisic acid (HGA) and phytyl diphosphate (PDP) as precursors. At least 5 enzymes 4-hydroxyphenylpyruvate dioxygenase (HPPD), homogentisate phytyl transferases (VTE2), 2-methyl-6-phytylbenzoquinol methyltransferase (VTE3), tocopherol cyclase (VTE1), $\gamma$-tocopherol methyltransferase (VTE4) are involved in the biosynthesis of tocopherols, excluding the bypass pathway of phytyl-tail synthesis and utilization [145]. Tocopherols are known to protect lipids and other membrane components by physically quenching and chemically reacting with $\mathrm{O}_{2}$ in chloroplasts, thus protecting the structure and function of PSII [146]. Tocopherols prevent the chain propagation step in lipid autooxidation which makes it an effective free radical trap. Fully substituted benzoquinone ring and fully reduced phytyl chain of tocopherol act as antioxidants in redox interactions with ${ }^{1} \mathrm{O}_{2}[105,147]$. ${ }^{1} \mathrm{O}_{2}$ oxygen quenching by tocopherols is highly efficient, and it is estimated that a single $\alpha$-tocopherol molecule can neutralize up to $220{ }^{1} \mathrm{O}_{2}$ molecules in vitro before being degraded [143]. Regeneration of the oxidized tocopherol back to its reduced form can be achieved by AsA, GSH [147] or coenzyme Q [148]. Accumulation of $\alpha$-tocopherol has been shown to induce tolerance to chilling, water deficit, and salinity in different plant species [149-152]. It was found that metabolic engineering of tocopherol biosynthetic pathway affected endogenous ascorbate and glutathione pools in leaves. Further study suggested that expression levels of genes encoding enzymes of Halliwell-Asada cycle were up-regulated, such as APX, DHAR and MDHAR [145]. Mutants of Arabidopsis thaliana with T-DNA insertions in tocopherol biosynthesis genes, tocopherol cyclase (vte1) and $\gamma$-tocopherol methyltransferase (vte4) showed higher concentration of protein carbonyl groups and GSSG compared to the wild type, indicating the development of oxidative stress [116]. Transgenic rice plants with Os-VTE1 RNA interference (OsVTE1-RNAi) were more sensitive to salt stress whereas, in contrast, transgenic plants overexpressing OsVTE1 (OsVTE1-OX) showed higher tolerance to salt stress [153]. OsVTE1-OX plants also accumulated less $\mathrm{H}_{2} \mathrm{O}_{2}$ than control plants.

3.1.4. Carotenoids. Carotenoids also belong to the group of lipophilic antioxidants and are able to detoxify various forms of ROS [154]. Carotenoids are found in plants as well as microorganisms. In plants, carotenoids absorb light in the region between 400 and $550 \mathrm{~nm}$ of the visible spectrum and pass the captured energy to the Chl [155]. As an antioxidant, they scavenge ${ }^{1} \mathrm{O}_{2}$ to inhibit oxidative damage and quench triplet sensitizer (3Chl*) and excited chlorophyll $\left(\mathrm{Chl}^{*}\right)$ molecule to prevent the formation of ${ }^{1} \mathrm{O}_{2}$ to protect the photosynthetic apparatus. Carotenoids also serve as precursors to signaling molecules that influence plant development and biotic/abiotic stress responses [156]. The ability of carotenoids to scavenge, prevent or minimize the production of triplet chlorophyll may be accounted for by their chemical specificity. Carotenoids contain a chain of isoprene residues bearing numerous conjugated double bonds which allows easy energy uptake from excited molecules and dissipation of excess energy as heat [7]. Gomathi and Rakkiyapan [157] observed that high carotenoids content favors better adaptation of sugarcane plants under saline condition. 
3.1.5. Phenolic Compounds. Phenolics are diverse secondary metabolites (flavonoids, tannins, hydroxycinnamate esters, and lignin) which possess antioxidant properties. They are abundantly found in plant tissues [158]. Polyphenols contain an aromatic ring with $-\mathrm{OH}$ or $\mathrm{OCH}_{3}$ substituents which together contribute to their biological activity, including antioxidant action. They have been shown to outperform well-known antioxidants, AsA and $\alpha$-tocopherol, in in vitro antioxidant assays because of their strong capacity to donate electrons or hydrogen atoms. Polyphenols can chelate transition metal ions, can directly scavenge molecular species of active oxygen, and can inhibit lipid peroxidation by trapping the lipid alkoxyl radical. They also modify lipid packing order and decrease fluidity of the membranes [159]. These changes could strictly hinder diffusion of free radicals and restrict peroxidative reactions. Moreover, it has been shown that, especially, flavonoids and phenylpropanoids are oxidized by peroxidase, and act in $\mathrm{H}_{2} \mathrm{O}_{2}$-scavenging, phenolic/AsA/POD system. There is some evidence of induction of phenolic metabolism in plants as a response to multiple stresses [160]. Janas and coworkers [161] observed that ROS could serve as a common signal for acclimation to $\mathrm{Cu}^{2+}$ stress and could cause accumulation of total phenolic compounds in darkgrown lentil roots. A mutant Arabidopsis thaliana L., having a single gene defect which led to a block in the synthesis of a group of flavonoids, displayed a dramatic increase in sensitivity to UV-B radiation compared with wild-type plants [162]. Transgenic potato plant with increased concentration of flavonoid showed improved antioxidant capacity [163].

3.2. Enzymatic Components. The enzymatic components of the antioxidative defense system comprise of several antioxidant enzymes such as superoxide dismutase (SOD), catalase (CAT), guaiacol peroxidase (GPX), enzymes of ascorbateglutathione (AsA-GSH) cycle ascorbate peroxidase (APX), monodehydroascorbate reductase (MDHAR), dehydroascorbate reductase (DHAR), and glutathione reductase (GR) [21]. These enzymes operate in different subcellular compartments and respond in concert when cells are exposed to oxidative stress. Table 1 shows various antioxidant enzymes that play important role in scavenging stress-induced ROS generated in plants.

3.2.1. Superoxide Dismutase. Superoxide dismutase (SOD, 1.15.1.1) plays central role in defense against oxidative stress in all aerobic organisms [175]. The enzyme SOD belongs to the group of metalloenzymes and catalyzes the dismutation of $\mathrm{O}_{2}{ }^{--}$to $\mathrm{O}_{2}$ and $\mathrm{H}_{2} \mathrm{O}_{2}$. It is present in most of the subcellular compartments that generate activated oxygen. Three isozymes of SOD copper/zinc SOD ( $\mathrm{Cu} / \mathrm{Zn}-\mathrm{SOD})$, manganese SOD (Mn-SOD), and iron SOD (Fe-SOD) are reported in plants [176, 177]. All forms of SOD are nuclear encoded and targeted to their respective subcellular compartments by an amino terminal targeting sequence [178]. MnSOD is localized in mitochondria, whereas FeSOD is localized in chloroplasts [179]. $\mathrm{Cu} / \mathrm{Zn}-\mathrm{SOD}$ is present in three isoforms, which are found in the cytosol, chloroplast, and peroxisome and mitochondria [178, 180-182]. Eukaryotic $\mathrm{Cu} / \mathrm{Zn}-\mathrm{SOD}$ is cyanide sensitive and presents as dimer, whereas the other two (Mn-SOD and Fe-SOD) are cyanide insensitive and may be dimer or tetramers [175, 182].

SOD activity has been reported to increase in plants exposed to various environmental stresses, including drought and metal toxicity [8, 13]. Increased activity of SOD is often correlated with increased tolerance of the plant against environmental stresses. It was suggested that SOD can be used as an indirect selection criterion for screening drought-resistant plant materials [22]. Overproduction of SOD has been reported to result in enhanced oxidative stress tolerance in plants [183].

3.2.2. Catalase. Among antioxidant enzymes, catalase (CAT, 1.11.1.6) was the first enzyme to be discovered and characterized. It is a ubiquitous tetrameric heme-containing enzyme that catalyzes the dismutation of two molecules of $\mathrm{H}_{2} \mathrm{O}_{2}$ into water and oxygen. It has high specificity for $\mathrm{H}_{2} \mathrm{O}_{2}$, but weak activity against organic peroxides. Plants contain several types of $\mathrm{H}_{2} \mathrm{O}_{2}$-degrading enzymes, however, CATs are unique as they do not require cellular reducing equivalent. CATs have a very fast turnover rate, but a much lower affinity for $\mathrm{H}_{2} \mathrm{O}_{2}$ than APX. The peroxisomes are major sites of $\mathrm{H}_{2} \mathrm{O}_{2}$ production. CAT scavenges $\mathrm{H}_{2} \mathrm{O}_{2}$ generated in this organelle during photorespiratory oxidation, $\beta$-oxidation of fatty acids, and other enzyme systems such as XOD coupled to SOD $[3,184,185]$. Though there are frequent reports of CAT being present in cytosol, chloroplast, and mitochondria, the presence of significant CAT activity in these is less well established [186]. To date, all angiosperm species studied, contain three CAT genes. Willekens et al. [187] proposed a classification of CAT based on the expression profile of the tobacco genes. Class I CATs are expressed in photosynthetic tissues and are regulated by light. Class II CATs are expressed at high levels in vascular tissues, whereas Class III CATs are highly abundant in seeds and young seedlings.

$\mathrm{H}_{2} \mathrm{O}_{2}$ has been implicated in many stress conditions. When cells are stressed for energy and are rapidly generating $\mathrm{H}_{2} \mathrm{O}_{2}$ through catabolic processes, $\mathrm{H}_{2} \mathrm{O}_{2}$ is degraded by CAT in an energy efficient manner [188]. Environmental stresses cause either enhancement or depletion of CAT activity, depending on the intensity, duration, and type of the stress $[8,10,189]$. In general, stresses that reduce the rate of protein turnover also reduce CAT activity. Stress analysis revealed increased susceptibility of CAT-deficient plants to paraquat, salt and ozone, but not to chilling [190]. In transgenic tobacco plants, having 10\% wild-type, CAT activity showed accumulation of GSSG and a 4-fold decrease in AsA, indicating that CAT is critical for maintaining the redox balance during the oxidative stress [190]. Overexpression of a CAT gene from Brassica juncea introduced into tobacco, enhanced its tolerance to Cd induced oxidative stress [191].

3.2.3. Guaiacol Peroxidase. Guaiacol peroxidase (GPX, EC 1.11.1.7), a heme containing protein, preferably oxidizes aromatic electron donor such as guaiacol and pyragallol at the expense of $\mathrm{H}_{2} \mathrm{O}_{2}$. It is widely found in animals, plants, 
TABLE 1: Activation of antioxidant enzymes in response to oxidative stress induced by various environmental stresses.

\begin{tabular}{|c|c|c|c|}
\hline Stresses & Antioxidant enzymes & Plant species & References \\
\hline \multirow{3}{*}{ Drought } & $\begin{array}{l}\text { SOD, GPX, APX, MDHAR, } \\
\text { DHAR and GR }\end{array}$ & Oryza sativa & {$[8]$} \\
\hline & SOD, CAT and GPX & Beta vulgaris & {$[164]$} \\
\hline & SOD, APX and GR & Triticum sativum & {$[165]$} \\
\hline \multirow{3}{*}{ Salinity } & SOD, CAT, GPX, APX, GR & Oryza sativa & {$[166]$} \\
\hline & CAT, SOD and GR & Olea europaea & {$[167]$} \\
\hline & GPX & Oryza sativa & {$[168]$} \\
\hline \multirow{2}{*}{ Chilling } & \multirow{2}{*}{$\begin{array}{l}\text { APX, MDHAR, DHAR, GR } \\
\text { and SOD }\end{array}$} & Zea mays & [169] \\
\hline & & Fragaria $\times$ ananassa & {$[170]$} \\
\hline MetalsAl & SOD, GPX and APX & $\begin{array}{l}\text { Oryza sativaGlycine } \\
\max \end{array}$ & {$[15,171]$} \\
\hline $\mathrm{Ni}$ & SOD, GPX and APX & Oryza sativa & {$[11]$} \\
\hline As & SOD, GPX and APX & Oryza sativa & {$[13]$} \\
\hline Mn & SOD, GPX, APX and GR & Oryza sativa & {$[14]$} \\
\hline \multirow[t]{2}{*}{ UV-B } & SOD, APX, CAT and GPX & Picea asperata & {$[10]$} \\
\hline & GPX andAPX & Arabidopsis thaliana & {$[172]$} \\
\hline $\begin{array}{l}\text { Pathogen Odium lini } \\
\text { fungus }\end{array}$ & GPX and CAT & Linum usitatissimum & {$[173]$} \\
\hline $\begin{array}{l}\text { Bean yellow mosaic } \\
\text { virus }\end{array}$ & POD, CAT, APX and SOD & Vicia faba & {$[174]$} \\
\hline
\end{tabular}

and microbes. These enzymes have four conserved disulfide bridges and contain two structural $\mathrm{Ca}^{2+}$ ions [192]. Many isoenzymes of GPX exist in plant tissues localized in vacuoles, the cell wall, and the cytosol [193]. GPX is associated with many important biosynthetic processes, including lignification of cell wall, degradation of IAA, biosynthesis of ethylene, wound healing, and defense against abiotic and biotic stresses [194]. GPXs are widely accepted as stress "enzyme." GPX can function as effective quencher of reactive intermediary forms of $\mathrm{O}_{2}$ and peroxy radicals under stressed conditions [195]. Various stressful conditions of the environment have been shown to induce the activity of GPX $[6,8,10,16,166$, $189,196]$. Radotic and coworkers [196] correlated increased activity of GPX to oxidative reactions under metal toxicity conditions and suggested its potential as biomarker for sublethal metal toxicity in plants. Recently, Tayefi-Nasrabadi and coworkers [197] also concluded that greater protection of salt-tolerant safflower plants from salt-induced oxidative damage results, at least in part, through the increase of the GPX activity, catalytic efficiency and induction of specific isoenzymes compared to salt-sensitive cultivar.

3.2.4. Enzymes of Ascorbate-Glutathione Cycle. The change in the ratio of AsA to DHA and GSH to GSSG is crucial for the cell to sense oxidative stress and respond accordingly. The AsA-GSH cycle also referred to as Halliwell-Asada pathway is the recycling pathway of AsA and GSH regeneration which also detoxifies $\mathrm{H}_{2} \mathrm{O}_{2}$. The AsA-GSH cycle involves successive oxidation and reduction of AsA, GSH, and NADPH catalyzed by the enzymes APX, MDHAR, DHAR, and GR. The AsAGSH cycle is present in at least four different subcellular locations, including the cytosol, chloroplast, mitochondria, and peroxisomes [198]. AsA-GSH cycle plays an important role in combating oxidative stress induced by environmental stresses $[8,199]$.

(1) Ascorbate Peroxidase. Ascorbate peroxidase (APX, EC 1.1.11.1) is a central component of AsA-GSH cycle, and plays an essential role in the control of intracellular ROS levels. APX uses two molecules of AsA to reduce $\mathrm{H}_{2} \mathrm{O}_{2}$ to water with a concomitant generation of two molecules of MDHA. APX is a member of Class I super family of heme peroxidases [200] and is regulated by redox signals and $\mathrm{H}_{2} \mathrm{O}_{2}$ [201]. Based on amino acid sequences, five chemically and enzymatically distinct isoenzymes of APX have been found at different subcellular localization in higher plants. These are cytosolic, stromal, thylakoidal, mitochondrial and peroxisomal isoforms [198, 202-204]. APX found in organelles scavenges $\mathrm{H}_{2} \mathrm{O}_{2}$ produced within the organelles, whereas cytosolic APX eliminates $\mathrm{H}_{2} \mathrm{O}_{2}$ produced in the cytosol, apoplast or that diffused from organelles [205]. The chloroplastic and cytosolic APX isoforms are specific for AsA as electron donor and the cytosolic isoenzymes are less sensitive to depletion of AsA than the chloroplastic isoenzymes, including stromal and thylakoid bound enzymes [203, 206].

APX is regarded as one of the most widely distributed antioxidant enzymes in plant cells and isoforms of APX have much higher affinity for $\mathrm{H}_{2} \mathrm{O}_{2}$ than CAT, making APXs efficient scavengers of $\mathrm{H}_{2} \mathrm{O}_{2}$ under stressful conditions [207]. Many workers have reported enhanced activity of APX in response to abiotic stresses such as drought, salinity, chilling, metal toxicity, and UV irradiation [8, 10, 11, 15, 136, 208]. Overexpression of a cytosolic APX-gene derived from pea 
(Pisum sativum L.) in transgenic tomato plants (Lycopersicon esculentum L.) ameliorated oxidative injury induced by chilling and salt stress [209]. Similarly, overexpression of the tApx gene in either tobacco or in Arabidopsis increased tolerance to oxidative stress [210].

(2) Monodehydroascorbate Reductase. MDHA radical produced in APX catalyzed reaction has a short lifetime, and if not rapidly reduced, it disproportionates to AsA and DHA [211]. Monodehydroascorbate reductase (MDHAR, 1.6.5.4) is a FAD enzyme that catalyzes the regeneration of AsA from the MDHA radical using $\mathrm{NAD}(\mathrm{P}) \mathrm{H}$ as the electron donor [212]. It is the only known enzyme to use an organic radical (MDA) as a substrate and is also capable of reducing phenoxyl radicals which are generated by horseradish peroxidase with $\mathrm{H}_{2} \mathrm{O}_{2}$ [213]. MDHAR activity is widespread in plants. The isoenzymes of MDHAR have been reported to be present in several cellular compartments such as chloroplasts [214], cytosol and mitochondria and peroxisomes [198, 215]. In chloroplasts, MDHAR could have two physiological functions: the regeneration of AsA from MDHA and the mediation of the photoreduction of dioxygen to $\mathrm{O}_{2}{ }^{--}$when the substrate MDHA is absent [216]. Characterization of membrane polypeptides from pea leaf peroxisomes also revealed MDHAR to be involved in $\mathrm{O}_{2}{ }^{\bullet-}$ generation [64].

Several studies have shown increased activity of MDHAR in plants subjected to environmental stresses [8, 11, 15, 208]. Overexpression of Arabidopsis MDHAR gene in tobacco confers enhanced tolerance to salt and polyethylene glycol stresses [217]. Tomato chloroplastic MDHAR overexpressed in transgenic Arabidopsis enhanced its tolerance to temperature and methyl viologen-mediated oxidative stresses [218].

(3) Dehydroascorbate Reductase. Dehydroascorbate reductase (DHAR, EC 1.8.5.1) catalyzes the reduction of DHA to AsA using GSH as the reducing substrate [211] and, thus, plays an important role in maintaining AsA in its reduced form. Despite the possibility of enzymic and nonenzymic regeneration of AsA directly from MDHA, some DHA is always produced when AsA is oxidized in leaves and other tissues. DHA, a very short-lived chemical, can either be hydrolyzed irreversibly to 2,3-diketogulonic acid or recycled to AsA by DHAR. Overexpression of DHAR in tobacco leaves, maize, and potato is reported to increase AsA content suggesting that DHAR plays important roles in determining the pool size of AsA $[219,220]$. DHAR is a monomeric thiol enzyme abundantly found in dry seeds, roots and etiolated as well as green shoots. DHAR has been purified from chloroplast as well as nonchloroplast sources in several plant species, including spinach leaves [221] and potato tuber [222].

Environmental stresses such as drought, metal toxicity, and chilling increase the activity of the DHAR in plants $[8,11,15,125,208,223]$. Consistent upregulation of the gene encoding cytosolic DHAR was found in L. japonicas, which was found to be more tolerant to salt stress than other legumes. This upregulation of DHAR was correlated to its role in AsA recycling in the apoplast [224]. Transgenic potato overexpressing Arabidopsis cytosolic AtDHAR1 showed higher tolerance to herbicide, drought, and salt stresses [225].

(4) Glutathione Reductase (GR). When acting as an antioxidant by participating in enzymic as well as nonenzymic oxidation-reduction cycles, GSH is oxidized to GSSG. In AsA-GSH cycle, GSH is oxidized in a reaction catalyzed by DHAR. Glutathione reductase (GR, EC 1.6.4.2), a $\mathrm{NAD}(\mathrm{P}) \mathrm{H}$-dependent enzyme catalyzes the reduction of GSSG to GSH and, thus, maintains high cellular GSH/GSSG ratio. GR belongs to a group of flavoenzymes and contains an essential disulfide group [226]. The catalytic mechanism involves two steps: first the flavin moiety is reduced by NADPH, the flavin is oxidized and a redox active disulfide bridge is reduced to produce a thiolate anion and a cysteine. The second step involves the reduction of GSSG via thioldisulfide interchange reactions [226]. If the reduced enzyme is not reoxidized by GSSG, it can suffer a reversible inactivation. Although it is located in the chloroplasts, cytosol, mitochondria, and peroxisomes, around $80 \%$ of GR activity in photosynthetic tissues is accounted for by chloroplastic isoforms [227]. In chloroplast, GSH and GR are involved in detoxification of $\mathrm{H}_{2} \mathrm{O}_{2}$ generated by Mehler reaction.

Several authors have reported increased activity of GR under environmental stresses [8, 11, 15, 125, 223]. Pastori and Trippi [228] observed correlation between the oxidative stress resistance and activity of GR and suggested that oxidative stress caused by paraquat or $\mathrm{H}_{2} \mathrm{O}_{2}$ could stimulate GR de novo synthesis, probably at the level of translation by preexisting mRNA. Antisense-mediated depletion of tomato chloroplast GR has been shown to enhance susceptibility to chilling stress [229]. Overexpression of GR in N. tabacum and Populus plants leads to higher foliar AsA contents and improved tolerance to oxidative stress $[138,230]$.

Due to the complexity of ROS detoxification system, overexpressing one component of antioxidative defense system may or may not change the capacity of the pathway as a whole $[231,232]$. Several studies have shown that overexpression of combinations of antioxidant enzymes in transgenic plants has synergistic effect on stress tolerance $[233,234]$. Kwon et al. [234] demonstrated that simultaneous expression of $\mathrm{Cu} / \mathrm{Zn}-\mathrm{SOD}$ and APX genes in tobacco chloroplasts enhanced tolerance to methyl viologen (MV) stress compared to expression of either of these genes alone. Similarly, enhanced tolerance to multiple environmental stresses has been developed by simultaneous overexpression of the genes of SOD and APX in the chloroplasts [235, 236], SOD and CAT in cytosol [231] and SOD and GR in cytosol [233]. Further, simultaneous expression of multiple antioxidant enzymes, such as $\mathrm{Cu} / \mathrm{Zn}-\mathrm{SOD}, \mathrm{APX}$, and DHAR, in chloroplasts has shown to be more effective than single or double expression for developing transgenic plants with enhanced tolerance to multiple environmental stresses [26]. Therefore, in order to achieve tolerance to multiple environmental stresses, increased emphasis is now given to produce transgenic plants overexpressing multiple antioxidants. 


\section{Overproduction of ROS under Stressful Conditions}

The production of ROS in plants under normal growth conditions is low. However, in response to various environmental stresses, ROS are drastically increased in plants disturbing the normal balance of $\mathrm{O}_{2}{ }^{\bullet-}, \cdot \mathrm{OH}$, and $\mathrm{H}_{2} \mathrm{O}_{2}$ in the intracellular environment [113]. The effects of various environmental stresses such as drought, salinity, chilling, metal toxicity, UV-B radiation, and pathogen attack on ROS production are discussed below.

4.1. Drought. Under drought stress, ROS production is enhanced in several ways. Inhibition of carbon dioxide $\left(\mathrm{CO}_{2}\right)$ assimilation, coupled with the changes in photosystem activities and photosynthetic transport capacity under drought stress results in accelerated production of ROS via the chloroplast Mehler reaction [237]. During drought stress, $\mathrm{CO}_{2}$ fixation is limited due to stomatal closure which, in turn, leads to reduced $\mathrm{NADP}^{+}$regeneration through the Calvin cycle. Due to lack of electron acceptor, over reduction of the photosynthetic ETC occurs which leads to a higher leakage of electrons to $\mathrm{O}_{2}$ by the Mehler reaction. Biehler and Fock [238] reported 50\% more leakage of photosynthetic electrons to the Mehler reaction in drought stressed wheat plants, compared to unstressed plants. Photosynthetic activity is inhibited in plant tissues due to an imbalance between light capture and its utilization under drought stress [239]. Dissipation of excess light energy in the PSII core and antenna leads to generation of ROS which are potentially dangerous under drought stress conditions [1]. Under drought stress, the photorespiratory pathway is also enhanced, especially, when RUBP oxygenation is maximal due to limitation in $\mathrm{CO}_{2}$ fixation [63]). Noctor and collaborators [63] have estimated that photorespiration is likely to account for over $70 \%$ of total $\mathrm{H}_{2} \mathrm{O}_{2}$ production under drought stress conditions.

$\mathrm{O}_{2}{ }^{\bullet-}$ initiates a chain reaction leading to the production of more toxic radical species, which may cause damage far in excess of the initial reaction products. Under drought stress one of the real threats towards the chloroplast is the production of the ${ }^{\cdot} \mathrm{OH}$ in the thylakoids through "ironcatalysed" reduction of $\mathrm{H}_{2} \mathrm{O}_{2}$ by both SOD and AsA. Increased production of ROS leads to oxidative stress in growing plants. Rice seedlings subjected to drought showed increased concentration of $\mathrm{O}_{2}{ }^{\bullet-}$, increased level of lipid peroxidation, chlorophyll bleaching, loss of some antioxidants (AsA, GSH, $\alpha$-tocopherol, and carotenoids), total soluble protein, and thiols $[8,208]$. To combat danger posed by ROS, plants possess different scavenging enzymes and metabolites. Enhanced activity of enzymes of antioxidative defense system has been reported under drought stress in several plant species $[8,164,165,208]$. Comparative study of the antioxidant responses in drought tolerant and drought sensitive genotypes revealed higher antioxidant capacity in tolerant genotypes. In contrast to drought susceptible wheat genotype HD 2329, drought tolerant wheat genotype C 306 had higher APX and CAT activity, higher AsA content and lower $\mathrm{H}_{2} \mathrm{O}_{2}$ and MDA content [240]. In another study, the drought tolerant maize genotype Giza 2 was suggested to be comparatively tolerant to water stress compared to drought sensitive Trihybrid 321 owing to the lower increase in $\mathrm{H}_{2} \mathrm{O}_{2}$ and MDA content along with higher increase in SOD, CAT, and POX activities [189]. Similarly, among two apple rootstocks Malus prunifolia (drought-tolerant) and M. hupehensis (drought-sensitive), M. hupehensis was more vulnerable to drought than $M$. prunifolia, resulting in larger increases in the levels of $\mathrm{H}_{2} \mathrm{O}_{2}, \mathrm{O}_{2}{ }^{--}$, and MDA. The activities of SOD, POD, APX, GR, and DHAR and levels of AsA and GSH increased to a greater extent in M. prunifolia than in $M$. hupehensis in response to drought [241]. APX serves as an important component of antioxidative defense system under drought [8]. In rice plants, increase in the capacity of AsA regeneration system by de novo synthesis of MDHAR, DHAR, and GR has been shown to be one of the primary responses to water deficit so as to mitigate oxidative stress $[8,208]$.

4.2. Salinity. Salinity stress results in an excessive generation of $\operatorname{ROS}[12,242]$. High salt concentrations lead to overproduction of the ROS- $\mathrm{O}_{2}{ }^{\bullet-},{ }^{\bullet} \mathrm{OH}, \mathrm{H}_{2} \mathrm{O}_{2}$, and ${ }^{1} \mathrm{O}_{2}$ by impairment of the cellular electron transport within different subcellular compartments such as chloroplasts and mitochondria, as well as from induction of metabolic pathways such as photorespiration. Salt stress can lead to stomatal closure, which reduces $\mathrm{CO}_{2}$ availability in the leaves and inhibits carbon fixation which, in turn, causes exposure of chloroplasts to excessive excitation energy and overreduction of photosynthetic electron transport system leading to enhanced generation of ROS and induced oxidative stress. Low chloroplastic $\mathrm{CO}_{2} / \mathrm{O}_{2}$ ratio also favors photorespiration leading to increased production of ROS such as $\mathrm{H}_{2} \mathrm{O}_{2}$ [242]. Elevated $\mathrm{CO}_{2}$ mitigates the oxidative stress caused by salinity, involving lower ROS generation and a better maintenance of redox homeostasis as a consequence of higher assimilation rates and lower photorespiration [243]. Salinity-induced ROS disrupt normal metabolism through lipid peroxidation, denaturing proteins, and nucleic acids in several plant species $[12,242,244]$. Differential genomic and proteomic screenings carried out in Physcomitrella patens plants showed that they responded to salinity stress by upregulating a large number of genes involved in antioxidant defense mechanism [245] suggesting that the antioxidative system may play a crucial role in protecting cells from oxidative damage following exposure to salinity stress in P. patens. Salinityinduced oxidative stress and possible relationship between the status of the components of antioxidative defense system and the salt tolerance in Indica rice (Oryza sativa L.) genotypes were studied by Mishra et al. [166]. Seedlings of salt-sensitive cultivar showed a substantial increase in the rate of $\mathrm{O}_{2}{ }^{--}$production, elevated levels of $\mathrm{H}_{2} \mathrm{O}_{2}, \mathrm{MDA}$, declined levels of thiol, AsA and GSH and lower activity of antioxidant enzymes compared to salt-tolerant seedlings. It was suggested that a higher status of antioxidants AsA and GSH and a coordinated higher activity of the enzymes SOD, CAT, GPX, APX, and GR can serve as the major 
determinants in the model for depicting salt tolerance in Indica rice seedlings [166]. Similarly, study of immediate responses (enzymatic and nonenzymatic) to salinity-induced oxidative stress in two major rice (Oryza sativa L.) cultivars, salt sensitive Pusa Basmati 1 (PB) and salt-tolerant Pokkali (PK), revealed a lesser extent of membrane damage (lipid peroxidation), lower levels of $\mathrm{H}_{2} \mathrm{O}_{2}$, higher activity of the ROS scavenging enzyme, CAT and enhanced levels of antioxidants like ASA and GSH in PK compared to PB [246]. Comparative study using cultivated tomato Lycopersicon esculentum Mill. $c v$. M82 (Lem) and its wild salt-tolerant relative L. pennellii (Corr.) D'Arcy accession Atico (Lpa) showed better protection of Lpa roots from salt-induced oxidative damage, at least partially, from the increased activities of the SOD, CAT, APX, MDHAR, and increased contents of AsA and GSH [247]. In salt-stressed root of Lem, a gradual increase in the membrane lipid peroxidation was observed, whereas no change in lipid peroxidation was observed in Lpa. Salt-tolerant Plantago maritima showed a lower level of MDA and a better protection mechanism against oxidative damage caused by salt stress by increasing activities of SOD, CAT, GR, and APX than the salt-sensitive $P$. media [248]. NADP-dehydrogenases and peroxidase have been suggested as key antioxidative enzymes in olive plants under salt stress conditions [167]. Mittal and Dubey [168] observed a correlation between peroxidase activity and salt tolerance in rice seedling.

4.3. Chilling. Chilling stress is a key environmental factor limiting growth and productivity of crop plants. Chilling leads to the overproduction of ROS by exacerbating imbalance between light absorption and light use by inhibiting Calvin-Benson cycle activity [249], enhancing photosynthetic electron flux to $\mathrm{O}_{2}$ and causing overreduction of respiratory ETC [9]. Chilling stress also causes significant reductions in $r b c \mathrm{~L}$ and $r b c \mathrm{~S}$ transcripts, RUBISCO content and initial RUBISCO activity, leading to higher electron flux to $\mathrm{O}_{2}$ [250]. $\mathrm{H}_{2} \mathrm{O}_{2}$ accumulation in chloroplast was negatively correlated with the initial RUBISCO activity and photosynthetic rate [250]. Chilling-induced oxidative stress evident by increased accumulation of ROS, including $\mathrm{H}_{2} \mathrm{O}_{2}$ and $\mathrm{O}_{2}{ }^{\bullet-}$, lipid peroxidation, and protein oxidation is a significant factor in relation to chilling injury in plants $[169,251,252]$. Protein carbonyl content, an indication of oxidative damage, was increased 2 -fold in maize seedlings when exposed to chilling temperatures [251]. Lipoxygenase activity as well as lipid peroxidation was increased in maize leaves during low temperatures, suggesting that lipoxygenase-mediated peroxidation of membrane lipids contributes to the oxidative damage occurring in chillstressed maize leaves [169]. Responses to chilling-induced oxidative stress include alteration in activities of enzymes of antioxidant defense system. The activities of antioxidative enzymes APX, MDHAR, DHAR, GR, and SOD increased during chilling periods in maize [169] and strawberry leaves [170]. However, if the duration of chilling stress is too long, the defense system may not remove overproduced ROS effectively, which may result in severe damage or even death [252]. Nonenzymic antioxidants (AsA, GSH, carotenoids, and $\alpha$-tocopherol) also play important role in cold response. Under cold stress conditions, low-molecular weight antioxidants, especially, that of reduced AsA, have been suggested to be an important component in plant cell defense [126]. Many comparative studies using chillingtolerant and sensitive genotypes have shown greater antioxidant capacity in chilling-tolerant species compared to sensitive ones [253-255]. In rice, higher activities of defense enzymes and higher content of antioxidant under stress were associated with tolerance to chilling [255]. The responses of antioxidative system of rice to chilling were investigated in a tolerant cultivar, Xiangnuo-1, and a susceptible cultivar, IR-50. The electrolyte leakage and malondialdehyde content of Xiangnuo- 1 were little affected by chilling treatment, but those of IR-50 increased. Activities of SOD, CAT, APX, and GR and AsA content of Xiangnuo-1 remained high, while those of IR-50 decreased under chilling stress. GR activity was also found to increase within $24 \mathrm{~h}$ in chilling-tolerant Zea diploperennis, but it decreased slightly in chilling-susceptible Z. mays $c v$. LG11 [253].

4.4. Metal Toxicity. The increasing levels of metals into the environment drastically affect plant growth and metabolism, ultimately, leading to severe losses in crop yields [256, 257]. One of the consequences of the presence of the toxic metals within the plant tissues is the formation of ROS, which can be initiated directly or indirectly by the metals and, consequently, leading to oxidative damage to different cell constituents $[6,11,14,15,258]$. Under metal stress condition, net photosynthesis $\left(\mathrm{Ph}_{\mathrm{n}}\right)$ decreases due to damage to photosynthetic metabolism, including photosynthetic electron transport $\left(\mathrm{Ph}_{\mathrm{et}}\right)$ [259]. For example, copper has been shown to negatively affect components of both the light reactions (e.g., PSII, thylakoid membrane structure, and chlorophyll content) [259] and $\mathrm{CO}_{2}$-fixation reactions [260]. These alterations in photosynthetic metabolism lead to overproduction of ROS such as $\mathrm{O}_{2}{ }^{--}, \cdot \mathrm{OH}$, and $\mathrm{H}_{2} \mathrm{O}_{2}$. The induction of ROS production due to metals (cadmium and zinc) in Nicotiana tabacum L. cv. Bright Yellow 2 (TBY2) cells in suspension cultures showed properties comparable to the elicitor-induced oxidative burst in other plant cells [261]. Redox-active metals, such as iron, copper, and chromium, undergo redox cycling producing ROS, whereas redox-inactive metals, such as lead, cadmium, mercury, and others, deplete cell's major antioxidants, particularly thiolcontaining antioxidants and enzymes $[6,11,14-16,262-$ 264]. If metal-induced production of ROS is not adequately counterbalanced by cellular antioxidants, oxidative damage of lipids, proteins, and nucleic acids ensues [13-15, 43, 46, 265, 266]. Significant enhancement in lipid peroxidation and decline in protein thiol contents were observed when rice seedlings were subjected to $\mathrm{Al}, \mathrm{Ni}$, and $\mathrm{Mn}$ toxicity $[11,14,15]$.

The increased activity of antioxidative enzymes in metal stressed plants appears to serve as an important component of antioxidant defense mechanism of plants to combat metalinduced oxidative injury [6]. Responses of metal exposure 
to plants vary depending on plant species, tissues, stages of development, type of metal and its concentration. One of the key responses includes triggering of a series of defense mechanisms which involve enzymatic and nonenzymatic components $[6,11,13-16,262]$. Various groups of workers have reported increased activities of antioxidant enzymes like GPX, SOD, APX, MDHAR, DHAR, and GR as well as nonenzymic antioxidants in metal-treated plants and suggested involvement of antioxidant defense system in the adaptive response to metal ions $[6,11,13-16,171]$. However, results suggest that activation of antioxidant enzymes in response to oxidative stress induced by metals is not enough to confer tolerance to metal accumulation. Comparative study of antioxidative response of two maize lines differing in $\mathrm{Al}$ tolerance suggested that better protection of the Al tolerant maize roots from Al-induced oxidative damage results, at least partially, from the increased activity of their antioxidative system. After $24 \mathrm{~h}$ of $\mathrm{Al}$ exposure, a gradual increase in the membrane lipid peroxidation in Al-stressed root of the susceptible maize line was accompanied by decreased activities of the antioxidant enzymes SOD and POD. In contrast, increased activities of the SOD and POD were found in Al-treated roots of the tolerant maize line, in which the level of membrane lipid peroxidation remained almost unchanged [267]. Comparative antioxidant profiling of tolerant (TPM-1) and sensitive (TM-4) variety of Brassica juncea L. performed after exposure to arsenate $[\mathrm{As}(\mathrm{V})]$ and arsenite [As(III)] showed in general, better response of antioxidant enzymes and the level of glutathione in TPM1 than in TM-4 [268]. These responses presumably allowed TPM-1 to tolerate higher As concentrations as compared with that of TM-4 [268].

4.5. UV-B Radiations. UV-B radiation on plants is now of major concern to plant biologists due to the threat to productivity in global agriculture [269]. Enhanced UV-B significantly inhibits net photosynthetic rate. It has been shown that UV-B treatment results in decrease in the lightsaturated rate of $\mathrm{CO}_{2}$ assimilation, accompanied by decreases in carboxylation velocity and RUBISCO content and activity [270]. He and coworkers [271] observed marked decrease in the ratios of variable to maximum chlorophyll fluorescence yield and in the quantum yield of photosynthetic oxygen evolution in pea and rice leaves. Limited $\mathrm{CO}_{2}$ assimilation due to UV-B leads to excessive production of ROS which, in turn, cause oxidative damage in plants [10, 272]. Rao and coworkers [172] suggested that UV-B exposure generates activated oxygen species by increasing NADPH-oxidase activity. Plants must adapt to the deleterious effects of UV-B radiation because they are dependent on sunlight for photosynthesis and, therefore, cannot avoid exposure to UV-B radiation. Plants possess antioxidative enzymatic scavengers SOD, POD, CAT, and APX and nonenzymatic antioxidants like AsA, GSH, and carotenoids to keep the balance between the production and removal of ROS. In Picea asperata seedlings although enhanced UV-B (30\%) increased the efficiency of antioxidant defense system consisting of UV-B absorbing compounds, carotenoids, and antioxidant enzymes SOD, APX, CAT, and GPX [10], it induced overproduction of ROS and oxidative stress eventually. Peroxidaserelated enzymes were found to be preferentially induced by UV-B exposure in Arabidopsis [172]. Gao and Zhang [115] observed that AsA-deficient mutant $v t c 1$ was more sensitive to supplementary UV-B treatment than wild-type plants and, therefore, suggested that AsA could be considered as an important antioxidant for UV-B radiation.

4.6. Pathogens. One of the earliest cellular responses following successful pathogen recognition is oxidative burst involving production of ROS. Recognition of a variety of pathogens leads to generation of $\mathrm{O}_{2}{ }^{\bullet-}$, or its dismutation product $\mathrm{H}_{2} \mathrm{O}_{2}$ in apoplast $[273,274]$. Radwan and coworkers [174] observed higher $\mathrm{H}_{2} \mathrm{O}_{2}$ and MDA concentrations in Vicia faba leaves infected with bean yellow mosaic virus than those of the corresponding controls. Several enzymes have been implicated in apoplastic ROS production following successful pathogen recognition. The use of inhibitors pointed to plasma membrane NADPH oxidases and cell wall peroxidases as the two most likely biochemical sources [274]. The expression of these enzymes is induced following recognition of bacterial and fungal pathogens [275, 276]. Although the primary oxidative burst following pathogen recognition occurs in the apoplast, ROS can be produced in other cellular compartments like mitochondria and chloroplast. Abdollahi and Ghahremani [277] studied the role of chloroplasts in the interaction between Erwinia amylovora and host plants by using uracil as chloroplast ETC inhibitor. Uracil presence significantly reduced ROS generation during pathogen-host interaction, and ROS generation corresponded with the appearance of necrosis in all cultivars [277]. Liu and coworkers [278] showed that activation of the SIPK/Ntf4/WIPK cascade by pathogens actively promotes the generation of ROS in chloroplasts, which plays an important role in the signaling for and/or execution of HR cell death in plants. They concluded that chloroplast burst occur earlier than NADPH oxidase burst and mitochondria-generated ROS might be essential in accelerating the cell death process.

Differential regulation of antioxidant enzymes, in part mediated by SA, may contribute to increases in ROS and activation of defenses following infection [81, 279]. In tobacco, the reduction of CAT and APX activities resulted in plants hyperresponsive to pathogens [279]. Significant increase in the activities of POD and CAT was observed in leaves of flax lines infected with powdery mildew [173]. Increase in POD activity was much pronounced in tolerant lines than susceptible lines. Enhanced activities of POD, CAT, APX, and SOD were observed in Vicia faba leaves infected with bean yellow mosaic virus indicating that the ROSscavenging systems can have an important role in managing ROS generated in response to pathogens [174].

\section{Concluding Remarks}

ROS are unavoidable by products of normal cell metabolism. ROS are generated by electron transport activities of chloroplast, mitochondria, and plasma membrane or as 
a byproduct of various metabolic pathways localized in different cellular compartments. Under normal growth condition, ROS production in various cell compartments is low. However, various environmental stresses such as drought, salinity, chilling, metal toxicity, and UV-B, if prolonged over to a certain extent, disrupt the cellular homeostasis and enhance the production of ROS. ROS play two divergent roles in plants; in low concentrations they act as signaling molecules that mediate several plant responses in plant cells, including responses under stresses, whereas in high concentrations they cause exacerbating damage to cellular components. Enhanced level of ROS causes oxidative damage to lipid, protein, and DNA leading to altered intrinsic membrane properties like fluidity, ion transport, loss of enzyme activity, protein crosslinking, inhibition of protein synthesis, DNA damage, ultimately resulting in cell death. In order to avoid the oxidative damage, higher plants possess a complex antioxidative defense system comprising of nonenzymatic and enzymatic components. Although rapid progress has been made in recent years, there are many uncertainties and gaps in our knowledge of ROS formation and their effect on plants mainly due to short half-life and high reactivity of ROS. Study of formation and fate of ROS using advanced analytical techniques will help in developing broader view of the role of ROS in plants. Future progress in genomics, metabolomics, and proteomics will help in clear understanding of biochemical networks involved in cellular responses to oxidative stress. Improved understanding of these will be helpful in producing plants with in-built capacity of enhanced levels of tolerance to ROS using biotechnological approach.

\section{References}

[1] C. H. Foyer and J. Harbinson, "Oxygen metabolism and the regulation of photosynthetic electron transport," in Causes of Photooxidative Stresses and Amelioration of Defense Systems in Plants, C. H. Foyer and P. Mullineaux, Eds., pp. 1-42, CRC Press, Boca Raton, Fla, USA, 1994.

[2] C. H. Foyer, "Oxygen metabolism and electron transport in photosynthesis," in Molecular Biology of Free Radical Scavenging Systems, J. Scandalios, Ed., pp. 587-621, Cold Spring Harbor Laboratory Press, New York, NY, USA, 1997.

[3] L. A. Del Río, L. M. Sandalio, F. J. Corpas, J. M. Palma, and J. B. Barroso, "Reactive oxygen species and reactive nitrogen species in peroxisomes. Production, scavenging, and role in cell signaling," Plant Physiology, vol. 141, no. 2, pp. 330-335, 2006.

[4] O. Blokhina and K. V. Fagerstedt, "Reactive oxygen species and nitric oxide in plant mitochondria: origin and redundant regulatory systems," Physiologia Plantarum, vol. 138, no. 4, pp. 447-462, 2010.

[5] E. Heyno, V. Mary, P. Schopfer, and A. Krieger-Liszkay, "Oxygen activation at the plasma membrane: relation between superoxide and hydroxyl radical production by isolated membranes," Planta, vol. 234, no. 1, pp. 35-45, 2011.

[6] K. Shah, R. G. Kumar, S. Verma, and R. S. Dubey, "Effect of cadmium on lipid peroxidation, superoxide anion generation and activities of antioxidant enzymes in growing rice seedlings," Plant Science, vol. 161, no. 6, pp. 1135-1144, 2001.
[7] R. Mittler, "Oxidative stress, antioxidants and stress tolerance," Trends in Plant Science, vol. 7, no. 9, pp. 405-410, 2002.

[8] P. Sharma and R. S. Dubey, "Drought induces oxidative stress and enhances the activities of antioxidant enzymes in growing rice seedlings," Plant Growth Regulation, vol. 46, no. 3, pp. 209-221, 2005.

[9] W. H. Hu, X. S. Song, K. Shi, X. J. Xia, Y. H. Zhou, and J. $\mathrm{Q}$. Yu, "Changes in electron transport, superoxide dismutase and ascorbate peroxidase isoenzymes in chloroplasts and mitochondria of cucumber leaves as influenced by chilling," Photosynthetica, vol. 46, no. 4, pp. 581-588, 2008.

[10] C. Han, Q. Liu, and Y. Yang, "Short-term effects of experimental warming and enhanced ultraviolet-B radiation on photosynthesis and antioxidant defense of Picea asperata seedlings," Plant Growth Regulation, vol. 58, no. 2, pp. 153162, 2009.

[11] R. Maheshwari and R. S. Dubey, "Nickel-induced oxidative stress and the role of antioxidant defence in rice seedlings," Plant Growth Regulation, vol. 59, no. 1, pp. 37-49, 2009.

[12] G. Tanou, A. Molassiotis, and G. Diamantidis, "Induction of reactive oxygen species and necrotic death-like destruction in strawberry leaves by salinity," Environmental and Experimental Botany, vol. 65, no. 2-3, pp. 270-281, 2009.

[13] S. Mishra, A. B. Jha, and R. S. Dubey, "Arsenite treatment induces oxidative stress, upregulates antioxidant system, and causes phytochelatin synthesis in rice seedlings," Protoplasma, vol. 248, no. 3, pp. 565-577, 2011.

[14] S. Srivastava and R. S. Dubey, "Manganese-excess induces oxidative stress, lowers the pool of antioxidants and elevates activities of key antioxidative enzymes in rice seedlings," Plant Growth Regulation, pp. 1-16, 2011.

[15] P. Sharma and R. S. Dubey, "Involvement of oxidative stress and role of antioxidative defense system in growing rice seedlings exposed to toxic concentrations of aluminum," Plant Cell Reports, vol. 26, no. 11, pp. 2027-2038, 2007.

[16] S. Verma and R. S. Dubey, "Lead toxicity induces lipid peroxidation and alters the activities of antioxidant enzymes in growing rice plants," Plant Science, vol. 164, no. 4, pp. 645655, 2003.

[17] B. Meriga, B. K. Reddy, K. R. Rao, L. A. Reddy, and P. B. K. Kishor, "Aluminium-induced production of oxygen radicals, lipid peroxidation and DNA damage in seedlings of rice (Oryza sativa)," Journal of Plant Physiology, vol. 161, no. 1, pp. 63-68, 2004.

[18] R. Desikan, S. A.-H.-Mackerness S., J. T. Hancock, and S. J. Neill, "Regulation of the Arabidopsis transcriptome by oxidative stress," Plant Physiology, vol. 127, no. 1, pp. 159$172,2001$.

[19] S. Neill, R. Desikan, and J. Hancock, "Hydrogen peroxide signalling," Current Opinion in Plant Biology, vol. 5, no. 5, pp. 388-395, 2002.

[20] J. Yan, N. Tsuichihara, T. Etoh, and S. Iwai, "Reactive oxygen species and nitric oxide are involved in ABA inhibition of stomatal opening," Plant, Cell and Environment, vol. 30, no. 10, pp. 1320-1325, 2007.

[21] G. Noctor and C. H. Foyer, "Ascorbate and glutathione: keeping active oxygen under control," Annual Review of Plant Biology, vol. 49, pp. 249-279, 1998.

[22] M. Zaefyzadeh, R. A. Quliyev, S. M. Babayeva, and M. A. Abbasov, "The effect of the interaction between genotypes and drought stress on the superoxide dismutase and chlorophyll content in durum wheat landraces," Turkish Journal of Biology, vol. 33, no. 1, pp. 1-7, 2009. 
[23] Q. Chen, M. Zhang, and S. Shen, "Effect of salt on malondialdehyde and antioxidant enzymes in seedling roots of Jerusalem artichoke (Helianthus tuberosus L.)," Acta Physiologiae Plantarum, vol. 33, no. 2, pp. 273-278, 2010.

[24] R. D. Allen, R. P. Webb, and S. A. Schake, "Use of transgenic plants to study antioxidant defenses," Free Radical Biology and Medicine, vol. 23, no. 3, pp. 473-479, 1997.

[25] M. Faize, L. Burgos, L. Faize et al., "Involvement of cytosolic ascorbate peroxidase and $\mathrm{Cu} / \mathrm{Zn}$-superoxide dismutase for improved tolerance against drought stress," Journal of Experimental Botany, vol. 62, no. 8, pp. 2599-2613, 2011.

[26] Y. P. Lee, S. H. Kim, J. W. Bang, H. S. Lee, S. S. Kwak, and S. Y. Kwon, "Enhanced tolerance to oxidative stress in transgenic tobacco plants expressing three antioxidant enzymes in chloroplasts," Plant Cell Reports, vol. 26, no. 5, pp. 591-598, 2007.

[27] K. Asada and M. Takahashi, "Production and scavenging of active oxygen in photosynthesis," in Photoinhibition: Topics of Photosynthesis, D. J. Kyle, C. B. Osmond, and C. J. Arntzen, Eds., pp. 227-287, Elsevier, Amsterdam, The Netherlands, 9th edition, 1987.

[28] K. Apel and H. Hirt, "Reactive oxygen species: metabolism, oxidative stress, and signal transduction," Annual Review of Plant Biology, vol. 55, pp. 373-399, 2004.

[29] A. Krieger-Liszkay, "Singlet oxygen production in photosynthesis," Journal of Experimental Botany, vol. 56, no. 411, pp. 337-346, 2005.

[30] S. Hatz, J. D. C. Lambert, and P. R. Ogilby, "Measuring the lifetime of singlet oxygen in a single cell: addressing the issue of cell viability," Photochemical and Photobiological Sciences, vol. 6, no. 10, pp. 1106-1116, 2007.

[31] S. Hackbarth, J. Schlothauer, A. Preuß, and B. Röder, "New insights to primary photodynamic effects—singlet oxygen kinetics in living cells," Journal of Photochemistry and Photobiology B, vol. 98, no. 3, pp. 173-179, 2010.

[32] D. Wagner, D. Przybyla, R. Op Den Camp et al., "The genetic basis of singlet oxygen-induced stress response of Arabidopsis thaliana," Science, vol. 306, no. 5699, pp. 1183-1185, 2004.

[33] H. Kasai, "Analysis of a form of oxidative DNA damage, 8hydroxy-2'-deoxyguanosine, as a marker of cellular oxidative stress during carcinogenesis," Mutation Research, vol. 387, no. 3, pp. 147-163, 1997.

[34] A. Krieger-Liszkay, C. Fufezan, and A. Trebst, "Singlet oxygen production in photosystem II and related protection mechanism," Photosynthesis Research, vol. 98, no. 1-3, pp. 551-564, 2008.

[35] B. Halliwell and J. M. C. Gutteridge, "Oxygen toxicity, oxygen radicals, transition metals and disease," Biochemical Journal, vol. 219, no. 1, pp. 1-14, 1984.

[36] M. Valko, H. Morris, and M. T. D. Cronin, "Metals, toxicity and oxidative stress," Current Medicinal Chemistry, vol. 12, no. 10, pp. 1161-1208, 2005.

[37] B. Halliwell, "Generation of hydrogen peroxide, superoxide and hydroxyl radicals during the oxidation of dihydroxyfumaric acid by peroxidase," Biochemical Journal, vol. 163, no. 3, pp. 441-448, 1977.

[38] J. A. Imlay, "Pathways of oxidative damage," Annual Review of Microbiology, vol. 57, pp. 395-418, 2003.

[39] J. M. McCord, J. D. Crapo, and I. Fridovich, "Superoxide dismutase assay. a review of methodology," in Superoxide and Superoxide Dismutase, A. M. Michelson, J. M. McCord, and I. Fridovich, Eds., pp. 11-17, Academic press, London, UK, 1977.
[40] R. Mittler and B. A. Zilinskas, "Purification and characterization of pea cytosolic ascorbate peroxidase," Plant Physiology, vol. 97, no. 3, pp. 962-968, 1991.

[41] G. P. Bienert, A. L. B. Møller, K. A. Kristiansen et al., "Specific aquaporins facilitate the diffusion of hydrogen peroxide across membranes," Journal of Biological Chemistry, vol. 282, no. 2, pp. 1183-1192, 2007.

[42] M. A. Torres, J. L. Dangl, and J. D. G. Jones, “Arabidopsis gp9 ${ }^{\text {phox }}$ homologues Atrbohd and Atrbohf are required for accumulation of reactive oxygen intermediates in the plant defense response," Proceedings of the National Academy of Sciences of the United States of America, vol. 99, no. 1, pp. 517522, 2002.

[43] B. Halliwell and J. M. C. Gutteridge, Free Radicals in Biology and Medicine, Oxford University Press, Oxford, UK, 2rd edition, 1989.

[44] W. M. Kaiser, "Reversible inhibition of the calvin cycle and activation of oxidative pentose phosphate cycle in isolated intact chloroplasts by hydrogen peroxide," Planta, vol. 145, no. 4, pp. 377-382, 1979.

[45] R. C. Leegood and D. A. Walker, "Regulation of fructose-1,6bisphosphatase activity in leaves," Planta, vol. 156, no. 5, pp. 449-456, 1982.

[46] J. Dat, S. Vandenabeele, E. Vranová, M. Van Montagu, D. Inzé, and F. Van Breusegem, "Dual action of the active oxygen species during plant stress responses," Cellular and Molecular Life Sciences, vol. 57, no. 5, pp. 779-795, 2000.

[47] A. Rigo, R. Stevanato, A. Finazzi Agro', and G. Rotilio, “An attempt to evaluate the rate of the Haber Weiss reaction by using ${ }^{\circ} \mathrm{OH}$ radical scavengers," FEBS Letters, vol. 80, no. 1, pp. 130-132, 1977.

[48] C. H. Foyer, H. Lopez-Delgado, J. F. Dat, and I. M. Scott, "Hydrogen peroxide- and glutathione-associated mechanisms of acclimatory stress tolerance and signalling," Physiologia Plantarum, vol. 100, no. 2, pp. 241-254, 1997.

[49] E. Pinto, T. C. S. Sigaud-Kutner, M. A. S. Leitão, O. K. Okamoto, D. Morse, and P. Colepicolo, "Heavy metalinduced oxidative stress in algae," Journal of Phycology, vol. 39, no. 6, pp. 1008-1018, 2003.

[50] H. Ishida, Y. Nishimori, M. Sugisawa, A. Makino, and T. Mae, "The large subunit of ribulose-1,5-bisphosphate carboxylase/oxygenase is fragmented into $37-\mathrm{kDa}$ and $16-\mathrm{kDa}$ polypeptides by active oxygen in the lysates of chloroplasts from primary leaves of wheat," Plant and Cell Physiology, vol. 38, no. 4, pp. 471-479, 1997.

[51] S. Luo, H. Ishida, A. Makino, and T. Mae, " $\mathrm{Fe}^{2+}$-catalyzed site-specific cleavage of the large subunit of ribulose 1,5bisphosphate carboxylase close to the active site," Journal of Biological Chemistry, vol. 277, no. 14, pp. 12382-12387, 2002.

[52] E. F. Elstner, "Oxygen activation and oxygen toxicity," Annual Review of Plant Biology, vol. 33, pp. 73-96, 1982.

[53] E. F. Elstner, "Metabolism of activated oxygen species," in Biochemistry of Plants, D. D. Davies, Ed., pp. 253-315, Academic Press, London, UK, 1987.

[54] E. F. Elstner, "Mechanisms of oxygen activation in different compartments of plant cells," in Active Oxygen/Oxidative Stress and Plant Metabolism, E. J. Pell and K. L. Steffen, Eds., pp. 13-25, American Society of Plant Physiologists, Rockville, Md, USA, 1991.

[55] R. E. Cleland and S. C. Grace, "Voltammetric detection of superoxide production by photosystem II," FEBS Letters, vol. 457, no. 3, pp. 348-352, 1999. 
[56] A. Arora, R. K. Sairam, and G. C. Srivastava, "Oxidative stress and antioxidative system in plants," Current Science, vol. 82, no. 10, pp. 1227-1238, 2002.

[57] J. F. Turrens, "Mitochondrial formation of reactive oxygen species," Journal of Physiology, vol. 552, no. 2, pp. 335-344, 2003.

[58] M. P. Murphy, "How mitochondria produce reactive oxygen species," Biochemical Journal, vol. 417, no. 1, pp. 1-13, 2009.

[59] G. Noctor, R. De Paepe, and C. H. Foyer, "Mitochondrial redox biology and homeostasis in plants," Trends in Plant Science, vol. 12, no. 3, pp. 125-134, 2007.

[60] A. Y. Andreyev, Y. E. Kushnareva, and A. A. Starkov, "Mitochondrial metabolism of reactive oxygen species," Biochemistry (Moscow), vol. 70, no. 2, pp. 200-214, 2005.

[61] A. G. Rasmusson, D. A. Geisler, and I. M. Møller, "The multiplicity of dehydrogenases in the electron transport chain of plant mitochondria," Mitochondrion, vol. 8, no. 1, pp. 47-60, 2008.

[62] A. Baker and A. I. Graham, Plant Peroxisomes: Biochemistry, Cell Biology and Biotechnological Applications, Kluwer Academic Publishers, Dordrecht, The Netherlands, 2002.

[63] G. Noctor, S. Veljovic-Jovanovic, S. Driscoll, L. Novitskaya, and C. H. Foyer, "Drought and oxidative load in the leaves of $\mathrm{C}_{3}$ plants: a predominant role for photorespiration?" Annals of Botany, vol. 89, pp. 841-850, 2002.

[64] E. López-Huertas, F. J. Corpas, L. M. Sandalio, and L. A. Del Río, "Characterization of membrane polypeptides from pea leaf peroxisomes involved in superoxide radical generation," Biochemical Journal, vol. 337, no. 3, pp. 531-536, 1999.

[65] J. M. Kwak, I. C. Mori, Z. M. Pei et al., "NADPH oxidase AtrbohD and AtrbohF genes function in ROS-dependent ABA signaling in Arabidopsis," EMBO Journal, vol. 22, no. 11, pp. 2623-2633, 2003.

[66] G. G. Gross, "Cell wall-bound malate dehydrogenase from horseradish," Phytochemistry, vol. 16, no. 3, pp. 319-321, 1977.

[67] C. Martinez, J. L. Montillet, E. Bresson et al., "Apoplastic peroxidase generates superoxide anions in cells of cotton cotyledons undergoing the hypersensitive reaction to Xanthomonas campestris pv. malvacearum 18," Molecular PlantMicrobe Interactions, vol. 11, no. 11, pp. 1038-1047, 1998.

[68] M. J. Kim, S. Ciani, and D. P. Schachtman, "A peroxidase contributes to ros production during Arabidopsis root response to potassium deficiency," Molecular Plant, vol. 3, no. 2, pp. 420-427, 2010.

[69] P. Wojtaszek, "Oxidative burst: an early plant response to pathogen infection," Biochemical Journal, vol. 322, no. 3, pp. 681-692, 1997.

[70] B. G. Lane, "Oxalate, germins, and higher-plant pathogens," IUBMB Life, vol. 53, no. 2, pp. 67-75, 2002.

[71] A. Cona, G. Rea, R. Angelini, R. Federico, and P. Tavladoraki, "Functions of amine oxidases in plant development and defence," Trends in Plant Science, vol. 11, no. 2, pp. 80-88, 2006.

[72] P. C. Bethke and R. L. Jones, "Cell death of barley aleurone protoplasts is mediated by reactive oxygen species," Plant Journal, vol. 25, no. 1, pp. 19-29, 2001.

[73] Jung Hee Joo, Yun Soo Bae, and June Seung Lee, "Role of auxin-induced reactive oxygen species in root gravitropism," Plant Physiology, vol. 126, no. 3, pp. 1055-1060, 2001.

[74] G. Miller, V. Shulaev, and R. Mittler, "Reactive oxygen signaling and abiotic stress," Physiologia Plantarum, vol. 133, no. 3, pp. 481-489, 2008.
[75] L. Xiong, K. S. Schumaker, and J. K. Zhu, "Cell signaling during cold, drought, and salt stress," Plant Cell, vol. 14, pp. S165-S183, 2002.

[76] Y. Cheng and C. Song, "Hydrogen peroxide homeostasis and signaling in plant cells," Science in China. Series C, Life sciences, vol. 49, no. 1, pp. 1-11, 2006.

[77] Z. M. Pel, Y. Murata, G. Benning et al., "Calcium channels activated by hydrogen peroxide mediate abscisic acid signalling in guard cells," Nature, vol. 406, no. 6797, pp. 731734, 2000.

[78] R. Jannat, M. Uraji, M. Morofuji et al., "Roles of intracellular hydrogen peroxide accumulation in abscisic acid signaling in Arabidopsis guard cells," Journal of Plant Physiology, vol. 168, no. 16, pp. 1919-1926, 2011.

[79] E. Bahin, C. Bailly, B. Sotta, I. Kranner, F. Corbineau, and J. Leymarie, "Crosstalk between reactive oxygen species and hormonal signalling pathways regulates grain dormancy in barley," Plant, Cell and Environment, vol. 34, no. 6, pp. 980993, 2011.

[80] A. K. Nanda, E. Andrio, D. Marino, N. Pauly, and C. Dunand, "Reactive oxygen species during plant-microorganism early interactions," Journal of Integrative Plant Biology, vol. 52, no. 2, pp. 195-204, 2010.

[81] D. F. Klessig, J. Durner, R. Noad et al., "Nitric oxide and salicylic acid signaling in plant defense," Proceedings of the National Academy of Sciences of the United States of America, vol. 97, no. 16, pp. 8849-8855, 2000.

[82] M. L. Orozco-Cárdenas, J. Narváez-Vásquez, and C. A. Ryan, "Hydrogen peroxide acts as a second messenger for the induction of defense genes in tomato plants in response to wounding, systemin, and methyl jasmonate," Plant Cell, vol. 13, no. 1, pp. 179-191, 2001.

[83] L. Denness, J. F. McKenna, C. Segonzac et al., "Cell wall damage-induced lignin biosynthesis is regulated by a reactive oxygen species- and jasmonic acid-dependent process in Arabidopsis," Plant Physiology, vol. 156, no. 3, pp. 1364-1374, 2011.

[84] T. Yuasa, K. Ichimura, T. Mizoguchi, and K. Shinozaki, "Oxidative stress activates ATMPK6, an Arabidopsis homologue of map kinase," Plant and Cell Physiology, vol. 42, no. 9, pp. 1012-1016, 2001.

[85] C. M. Yeh, P. S. Chien, and H. J. Huang, "Distinct signalling pathways for induction of MAP kinase activities by cadmium and copper in rice roots," Journal of Experimental Botany, vol. 58, no. 3, pp. 659-671, 2007.

[86] O. Borsani, P. Díaz, M. F. Agius, V. Valpuesta, and J. Monza, "Water stress generates an oxidative stress through the induction of a specific $\mathrm{Cu} / \mathrm{Zn}$ superoxide dismutase in Lotus corniculatus leaves," Plant Science, vol. 161, no. 4, pp. 757-763, 2001.

[87] Z. Zhao, G. Chen, and C. Zhang, "Interaction between reactive oxygen species and nitric oxide in drought-induced abscisic acid synthesis in root tips of wheat seedlings," Australian Journal of Plant Physiology, vol. 28, no. 10, pp. 1055-1061, 2001.

[88] N. Smirnoff, "Antioxidant systems and plant response to the environment," in Environment and Plant Metabolism: Flexibility and Acclimation, N. Smirnoff, Ed., pp. 217-243, Bios Scientific Publishers, Oxford, UK, 1995.

[89] R. O. Recknagal and E. A. Glende, "Oxygen radicals in biological systems," in Methods in Enzymology, L. Packer, Ed., vol. 105, pp. 331-337, Academic Press, New York, NY, USA, 1984. 
[90] K. J. A. Davies, "Oxidative stress, antioxidant defenses, and damage removal, repair, and replacement systems," IUBMB Life, vol. 50, no. 4-5, pp. 279-289, 2000.

[91] G. R. Buettner, "The pecking order of free radicals and antioxidants: lipid peroxidation, $\alpha$-tocopherol, and ascorbate," Archives of Biochemistry and Biophysics, vol. 300, no. 2, pp. 535-543, 1993.

[92] Y. Yamauchi, A. Furutera, K. Seki, Y. Toyoda, K. Tanaka, and Y. Sugimoto, "Malondialdehyde generated from peroxidized linolenic acid causes protein modification in heat-stressed plants," Plant Physiology and Biochemistry, vol. 46, no. 8-9, pp. 786-793, 2008.

[93] I. M. Møller and B. K. Kristensen, "Protein oxidation in plant mitochondria as a stress indicator," Photochemical and Photobiological Sciences, vol. 3, no. 8, pp. 730-735, 2004.

[94] M. C. Romero-Puertas, J. M. Palma, M. Gómez, L. A. Del Río, and L. M. Sandalio, "Cadmium causes the oxidative modification of proteins in pea plants," Plant, Cell and Environment, vol. 25, no. 5, pp. 677-686, 2002.

[95] S. J. Stohs and D. Bagchi, "Oxidative mechanisms in the toxicity of metal ions," Free Radical Biology and Medicine, vol. 18, no. 2, pp. 321-336, 1995.

[96] N. Brot and H. Weissbach, "The biochemistry of methionine sulfoxide residues in proteins," Trends in Biochemical Sciences, vol. 7, no. 4, pp. 137-139, 1982.

[97] K. J. Davies, "Protein damage and degradation by oxygen radicals. I. general aspects," Journal of Biological Chemistry, vol. 262, no. 20, pp. 9895-9901, 1987.

[98] P. R. Gardner and I. Fridovich, "Superoxide sensitivity of the Escherichia coli 6-phosphogluconate dehydratase," Journal of Biological Chemistry, vol. 266, no. 3, pp. 1478-1483, 1991.

[99] E. R. Stadtman, "Oxidation of proteins by mixed-function oxidation systems: implication in protein turnover, ageing and neutrophil function," Trends in Biochemical Sciences, vol. 11 , no. 1, pp. 11-12, 1986.

[100] E. Cabiscol, E. Piulats, P. Echave, E. Herrero, and J. Ros, "Oxidative stress promotes specific protein damage in Saccharomyces cerevisiae," Journal of Biological Chemistry, vol. 275, no. 35, pp. 27393-27398, 2000.

[101] T. Grune, T. Reinheckel, and K. J. A. Davies, "Degradation of oxidized proteins in mammalian cells," FASEB Journal, vol. 11, no. 7, pp. 526-534, 1997.

[102] J. A. Imlay and S. Linn, "DNA damage and oxygen radical toxicity," Science, vol. 240, no. 4857, pp. 1302-1309, 1988.

[103] T. Liu, J. Van Staden, and W. A. Cress, "Salinity induced nuclear and DNA degradation in meristematic cells of soybean (Glycine max (L.)) roots," Plant Growth Regulation, vol. 30, no. 1, pp. 49-54, 2000.

[104] M. Dizdaroglu, "Chemistry of free radical damage to DNA and nucleoproteins," in DNA and Free Radicals, B. Halliwell and O. I. Aruoma, Eds., pp. 19-39, Ellis Horwood, London, UK, 1993.

[105] B. Halliwell and J. M. C. Gutteridge, Free Radicals in Biology and Medicine, Oxford University Press, Oxford, UK, 3rd edition, 1999.

[106] H. Tsuboi, K. Kouda, H. Takeuchi et al., "8-Hydroxydeoxyguanosine in urine as an index of oxidative damage to DNA in the evaluation of atopic dermatitis," British Journal of Dermatology, vol. 138, no. 6, pp. 1033-1035, 1998.

[107] B. Halliwell and O. I. Aruoma, "DNA damage by oxygenderived species. Its mechanism and measurement in mammalian systems," FEBS Letters, vol. 281, no. 1-2, pp. 9-19, 1991.
[108] S. P. Fink, G. R. Reddy, and L. J. Marnett, "Mutagenicity in Escherichia coli of the major DNA adduct derived from the endogenous mutagen malondialdehyde," Proceedings of the National Academy of Sciences of the United States of America, vol. 94, no. 16, pp. 8652-8657, 1997.

[109] M. D. Evans, M. Dizdaroglu, and M. S. Cooke, "Oxidative DNA damage and disease: induction, repair and significance," Mutation Research, vol. 567, no. 1, pp. 1-61, 2004.

[110] N. L. Oleinick, Song-mao Chiu, N. Ramakrishnan, and Liang-yan Xue, "The formation, identification, and significance of DNA-protein cross-links in mammalian cells," British Journal of Cancer, supplement, vol. 8, pp. 135-140, 1987.

[111] C. Richter, "Reactive oxygen and DNA damage in mitochondria," Mutation Research, DNAging Genetic Instability and Aging, vol. 275, no. 3-6, pp. 249-255, 1992.

[112] C. H. Pang and B. S. Wang, "Oxidative stress and salt tolerance in plants," in Progress in Botany, U. Lüttge, W. Beyschlag, and J. Murata, Eds., pp. 231-245, Springer, Berlin, Germany, 2008.

[113] P. Sharma, A. B. Jha, and R. S. Dubey, "Oxidative stress and antioxidative defense system in plants growing under abiotic Stresses," in Handbook of Plant and Crop Stress, M. Pessarakli, Ed., pp. 89-138, CRC Press, Taylor and Francis Publishing Company, Fla, USA, 3rd edition, 2010.

[114] M. C. De Pinto and L. De Gara, "Changes in the ascorbate metabolism of apoplastic and symplastic spaces are associated with cell differentiation," Journal of Experimental Botany, vol. 55, no. 408, pp. 2559-2569, 2004.

[115] Q. Gao and L. Zhang, "Ultraviolet-B-induced oxidative stress and antioxidant defense system responses in ascorbatedeficient vtc1 mutants of Arabidopsis thaliana," Journal of Plant Physiology, vol. 165, no. 2, pp. 138-148, 2008.

[116] N. M. Semchuk, O. V. Lushchak, J. Falk, K. Krupinska, and V. I. Lushchak, "Inactivation of genes, encoding tocopherol biosynthetic pathway enzymes, results in oxidative stress in outdoor grown Arabidopsis thaliana," Plant Physiology and Biochemistry, vol. 47, no. 5, pp. 384-390, 2009.

[117] G. L. Wheeler, M. A. Jones, and N. Smirnoff, "The biosynthetic pathway of vitamin C in higher plants," Nature, vol. 393, no. 6683, pp. 365-369, 1998.

[118] F. A. Isherwood, Y. T. Chen, and L. W. Mapson, "Synthesis of L-ascorbic acid in plants and animals," The Biochemical Journal, vol. 56, no. 1, pp. 1-15, 1954.

[119] H. B. Shao, L. Y. Chu, Z. H. Lu, and C. M. Kang, "Primary antioxidant free radical scavenging and redox signaling pathways in higher plant cells," International Journal of Biological Sciences, vol. 4, no. 1, pp. 8-14, 2008.

[120] N. Smirnoff, J. A. Running, and S. Gatzek, "Ascorbate biosynthesis: a diversity of pathways," in Vitamin C: Its Functions and Biochemistry in Animals and Plants, H. Asard, J. M. May, and N. Smirnoff, Eds., pp. 7-29, BIOS Scientific, New York, NY, USA, 2004.

[121] J. D. Barnes, Y. Zheng, and T. M. Lyons, "Plant resistance to ozone: the role of ascorbate," in Air Pollution and Plant Biotechnology, K. Omasa, H. Saji, S. Youssefian, and N. Kondo, Eds., pp. 235-254, Springer, Tokyo, Japan, 2002.

[122] N. Smirnoff, "Ascorbic acid: metabolism and functions of a multi-facetted molecule," Current Opinion in Plant Biology, vol. 3, no. 3, pp. 229-235, 2000.

[123] C. Miyake and K. Asada, "Ferredoxin-dependent photoreduction of the monodehydroascorbate radical in spinach thylakoids," Plant and Cell Physiology, vol. 35, no. 4, pp. 539549, 1994. 
[124] K. Asada, "Radical production and scavenging in the chloroplasts," in Photosynthesis and the Environment, N. R. Baker, Ed., pp. 123-150, Kluwer, Dordrecht, The Netherlands, 1996.

[125] J. A. Hernández, M. A. Ferrer, A. Jiménez, A. R. Barceló, and F. Sevilla, "Antioxidant systems and $\mathrm{O}_{2}^{--} / \mathrm{H}_{2} \mathrm{O}_{2}$ production in the apoplast of pea leaves. Its relation with salt-induced necrotic lesions in minor veins," Plant Physiology, vol. 127, no. 3, pp. 817-831, 2001.

[126] M. S. Radyuk, I. N. Domanskaya, R. A. Shcherbakov, and N. V. Shalygo, "Effect of low above-zero temperature on the content of low-molecular antioxidants and activities of antioxidant enzymes in green barley leaves," Russian Journal of Plant Physiology, vol. 56, no. 2, pp. 175-180, 2009.

[127] M. M. Chaves, J. S. Pereira, J. Maroco et al., "How plants cope with water stress in the field. Photosynthesis and growth," Annals of Botany, vol. 89, pp. 907-916, 2002.

[128] C. Zhang, J. Liu, Y. Zhang et al., "Overexpression of SlGMEs leads to ascorbate accumulation with enhanced oxidative stress, cold, and salt tolerance in tomato," Plant Cell Reports, vol. 30, no. 3, pp. 389-398, 2011.

[129] Hemavathi, C. P. Upadhyaya, K. E. Young et al., "Overexpression of strawberry d-galacturonic acid reductase in potato leads to accumulation of vitamin $C$ with enhanced abiotic stress tolerance," Plant Science, vol. 177, no. 6, pp. 659-667, 2009.

[130] Z. Wang, Y. Xiao, W. Chen, K. Tang, and L. Zhang, "Increased vitamin $\mathrm{C}$ content accompanied by an enhanced recycling pathway confers oxidative stress tolerance in Arabidopsis," Journal of Integrative Plant Biology, vol. 52, no. 4, pp. 400409, 2010.

[131] C. H. Foyer and G. Noctor, "Redox sensing and signalling associated with reactive oxygen in chloroplasts, peroxisomes and mitochondria," Physiologia Plantarum, vol. 119, no. 3, pp. 355-364, 2003.

[132] K. Asada, "Production and action of active oxygen species in photosynthetic tissues," in Causes of Photooxidative Stress and Amelioration of Defense Systems in Plants, C. H. Foyer and P. M. Mullineaux, Eds., pp. 77-104, CRC Press, Boca Raton, Fla, USA, 1994.

[133] F. A. Loewus, "Ascorbic acid and its metabolic products," in The Biochemistry of Plants, J. Preiss, Ed., pp. 85-107, ,Academic Press, New York, NY, USA, 1988.

[134] C. H. Foyer and B. Halliwell, "The presence of glutathione and glutathione reductase in chloroplasts: a proposed role in ascorbic acid metabolism," Planta, vol. 133, no. 1, pp. 21-25, 1976.

[135] M. Tausz, H. Šircelj, and D. Grill, "The glutathione system as a stress marker in plant ecophysiology: is a stress-response concept valid?" Journal of Experimental Botany, vol. 55, no. 404, pp. 1955-1962, 2004.

[136] M. Hefny and D. Z. Abdel-Kader, "Antioxidant-enzyme system as selection criteria for salt tolerance in forage sorghum genotypes (Sorghum bicolor L. Moench)," in Salinity and Water Stress, M. Ashraf, M. Ozturk, and H. R. Athar, Eds., pp. 25-36, Springer, The Netherlands, 2009.

[137] M. Strohm, M. Eiblmeier, C. Langebartels et al., "Responses of transgenic poplar (Populus tremula $\times$ P. alba) overexpressing glutathione synthetase or glutathione reductase to acute ozone stress: visible injury and leaf gas exchange," Journal of Experimental Botany, vol. 50, no. 332, pp. 365-374, 1999.

[138] C. H. Foyer, N. Souriau, S. Perret et al., "Overexpression of glutathione reductase but not glutathione synthetase leads to increases in antioxidant capacity and resistance to photoinhibition in poplar trees," Plant Physiology, vol. 109, no. 3, pp. 1047-1057, 1995.

[139] Y. L. Zhu, E. A. H. Pilon-Smits, A. S. Tarun, S. U. Weber, L. Jouanin, and N. Terry, "Cadmium tolerance and accumulation in Indian mustard is enhanced by overexpressing $\gamma$ glutamylcysteine synthetase," Plant Physiology, vol. 121, no. 4, pp. 1169-1177, 1999.

[140] G. Gullner, T. Kömives, and H. Rennenberg, "Enhanced tolerance of transgenic poplar plants overexpressing $\gamma$ glutamylcysteine synthetase towards chloroacetanilide herbicides," Journal of Experimental Botany, vol. 52, no. 358, pp. 971-979, 2001.

[141] A. E. Eltayeb, S. Yamamoto, M. E. E. Habora et al., "Greater protection against oxidative damages imposed by various environmental stresses in transgenic potato with higher level of reduced glutathione," Breeding Science, vol. 60, no. 2, pp. 101-109, 2010.

[142] T. Diplock, L. J. Machlin, L. Packer, and W. A. Pryor, "Vitamin E: biochemistry and health implications," Annals of the New York Academy of Sciences, vol. 570, pp. 372-378, 1989.

[143] K. Fukuzawa, A. Tokumura, S. Ouchi, and H. Tsukatani, "Antioxidant activities of tocopherols on $\mathrm{Fe}^{2+}$-ascorbateinduced lipid peroxidation in lecithin liposomes," Lipids, vol. 17, no. 7, pp. 511-514, 1982.

[144] A. Kamal-Eldin and L. Å. Appelqvist, "The chemistry and antioxidant properties of tocopherols and tocotrienols," Lipids, vol. 31, no. 7, pp. 671-701, 1996.

[145] Y. Li, Y. Zhou, Z. Wang, X. Sun, and K. Tang, "Engineering tocopherol biosynthetic pathway in Arabidopsis leaves and its effect on antioxidant metabolism," Plant Science, vol. 178, no. 3, pp. 312-320, 2010.

[146] B. N. Ivanov and S. Khorobrykh, "Participation of photosynthetic electron transport in production and scavenging of reactive oxygen species," Antioxidants and Redox Signaling, vol. 5, no. 1, pp. 43-53, 2003.

[147] M. J. Fryer, "The antioxidant effect of thylakoid vitamin-E ( $\alpha$-tocopherol)," Plant, Cell and Environment, vol. 15, no. 4, pp. 381-392, 1992.

[148] V. E. Kagan, J. P. Fabisiak, and P. J. Quinn, "Coenzyme Q and vitamin E need each other as antioxidants," Protoplasma, vol. 214, no. 1-2, pp. 11-18, 2000.

[149] K. Yamaguchi-Shinozaki and K. Shinozaki, "A novel cis element in an Arabidopsis gene is involved in responsiveness to drought, low-temperature, or high-salt stress," Plant Cell, vol. 6, no. 2, pp. 251-264, 1994.

[150] S. Munné-Bosch, K. Schwarz, and L. Alegre, "Enhanced formation of $\alpha$-tocopherol and highly oxidized abietane diterpenes in water-stressed rosemary plants," Plant Physiology, vol. 121, no. 3, pp. 1047-1052, 1999.

[151] J. Guo, X. Liu, X. Li, S. Chen, Z. Jin, and G. Liu, "Overexpression of VTE1 from Arabidopsis resulting in high vitamin $\mathrm{E}$ accumulation and salt stress tolerance increase in tobacco plant," Chinese Journal of Applied and Environmental Biology, vol. 12, no. 4, pp. 468-471, 2006.

[152] S. O. Bafeel and M. M. Ibrahim, "Antioxidants and accumulation of $\alpha$-tocopherol induce chilling tolerance in Medicago sativa," International Journal of Agriculture and Biology, vol. 10, no. 6, pp. 593-598, 2008.

[153] S. Q. Ouyang, S. J. He, P. Liu, W. K. Zhang, J. S. Zhang, and S. Y. Chen, "The role of tocopherol cyclase in salt stress tolerance of rice (Oryza sativa)," Science China Life Sciences, vol. 54, no. 2, pp. 181-188, 2011. 
[154] J. Young, "The photoprotective role of carotenoids in higher plants," Physiologia Plantarum, vol. 83, no. 4, pp. 702-708, 1991.

[155] D. Sieferman-Harms, "The light harvesting function of carotenoids in photosynthetic membrane," Plant Physiology, vol. 69, no. 3, pp. 561-568, 1987.

[156] F. Li, R. Vallabhaneni, J. Yu, T. Rocheford, and E. T. Wurtzel, "The maize phytoene synthase gene family: overlapping roles for carotenogenesis in endosperm, photomorphogenesis, and thermal stress tolerance," Plant Physiology, vol. 147, no. 3, pp. 1334-1346, 2008.

[157] R. Gomathi and P. Rakkiyapan, "Comparative lipid peroxidation, leaf membrane thermostability, and antioxidant system in four sugarcane genotypes differing in salt tolerance," International Journal of Plant Physiology and Biochemistry, vol. 3, no. 4, pp. 67-74, 2011.

[158] S. G. Grace and B. A. Logan, "Energy dissipation and radical scavenging by the plant phenylpropanoid pathway," Philosophical Transactions of the Royal Society B, vol. 355, no. 1402, pp. 1499-1510, 2000.

[159] A. Arora, T. M. Byrem, M. G. Nair, and G. M. Strasburg, "Modulation of liposomal membrane fluidity by flavonoids and isoflavonoids," Archives of Biochemistry and Biophysics, vol. 373, no. 1, pp. 102-109, 2000.

[160] A. Michalak, "Phenolic compounds and their antioxidant activity in plants growing under heavy metal stress," Polish Journal of Environmental Studies, vol. 15, no. 4, pp. 523-530, 2006.

[161] K. M. Janas, R. Amarowicz, J. Zielińska-Tomaszewska, A. Kosińska, and M. M. Posmyk, "Induction of phenolic compounds in two dark-grown lentil cultivars with different tolerance to copper ions," Acta Physiologiae Plantarum, vol. 31, no. 3, pp. 587-595, 2009.

[162] R. Lois and B. B. Buchanan, "Severe sensitivity to ultraviolet radiation in an Arabidopsis mutant deficient in flavonoid accumulation. II.Mechanisms of UV-resistance in Arabidopsis," Planta, vol. 194, no. 4, pp. 504-509, 1994.

[163] M. Lukaszewicz, I. Matysiak-Kata, J. Skala, I. Fecka, W. Cisowski, and J. Szopa, "Antioxidant capacity manipulation in transgenic potato tuber by changes in phenolic compounds content," Journal of Agricultural and Food Chemistry, vol. 52, no. 6, pp. 1526-1533, 2004.

[164] S. Sayfzadeh and M. Rashidi, "Response of antioxidant enzymes activities of sugar beet to drought stress," ARPN Journal of Agricultural and Biological Science, vol. 6, no. 4, pp. 27-33, 2011.

[165] C. Sgherri, B. Stevanovic, and F. Navari-Izzo, "Role of phenolic acids during dehydration and rehydration of Ramonda serbica," Physiologia Plantarum, vol. 122, no. 4, pp. 478-485, 2000.

[166] P. Mishra, B. Kumari, and R. S. Dubey, "Differential responses of antioxidative defense system to prolonged salinity stress in salt-tolerant and salt-sensitive Indica rice (Oryza sativa L.) seedlings," Protoplasma. In press.

[167] R. Valderrama, F. J. Corpas, A. Carreras et al., "The dehydrogenase-mediated recycling of NADPH is a key antioxidant system against salt-induced oxidative stress in olive plants," Plant, Cell and Environment, vol. 29, no. 7, pp. 1449-1459, 2006.

[168] R. Mittal and R. S. Dubey, "Behaviour of peroxidases in rice: changes in enzymatic activity and isoforms in relation to salt tolerance," Plant Physiology and Biochemistry, vol. 29, no. 1, pp. 31-40, 1991.
[169] M. J. Fryer, J. R. Andrews, K. Oxborough, D. A. Blowers, and N. R. Baker, "Relationship between $\mathrm{CO}_{2}$ assimilation, photosynthetic electron transport, and active $\mathrm{O}_{2}$ metabolism in leaves of maize in the field during periods of low temperature," Plant Physiology, vol. 116, no. 2, pp. 571-580, 1998.

[170] Y. Zhang, Y. Luo, Y. X. Hou, H. Jiang, Q. Chen, and R. H. Tang, "Chilling acclimation induced changes in the distribution of $\mathrm{H}_{2} \mathrm{O}_{2}$ and antioxidant system of strawberry leaves," Agricultural Journal, vol. 3, no. 4, pp. 286-291, 2008.

[171] I. Cakmak and W. J. Horst, "Effect of aluminium on lipid peroxidation, superoxide dismuatse, catalase, and peroxidase activities in root tips of soybean (Glycine max)," Physiologia Plantarum, vol. 83, no. 3, pp. 463-468, 1991.

[172] M. V. Rao, G. Paliyath, and D. P. Ormrod, "Ultraviolet-B- and ozone-induced biochemical changes in antioxidant enzymes of Arabidopsis thaliana," Plant Physiology, vol. 110, no. 1, pp. 125-136, 1996.

[173] N. A. Ashry and H. I. Mohamed, "Impact of secondary metabolites and related enzymes in flax resistance and/or susceptibility to powdery mildew," African Journal of Biotechnology, vol. 11, no. 5, pp. 1073-1077, 2012.

[174] D. E. M. Radwan, K. A. Fayez, S. Y. Mahmoud, and G. Lu, "Modifications of antioxidant activity and protein composition of bean leaf due to Bean yellow mosaic virus infection and salicylic acid treatments," Acta Physiologiae Plantarum, vol. 32, no. 5, pp. 891-904, 2010.

[175] J. G. Scandalios, "Oxygen stress and superoxide dismutases," Plant Physiology, vol. 101, no. 1, pp. 7-12, 1993.

[176] I. Fridovich, "Superoxide dismutases. An adaptation to a paramagnetic gas," Journal of Biological Chemistry, vol. 264, no. 14, pp. 7761-7764, 1989.

[177] M. L. Racchi, F. Bagnoli, I. Balla, and S. Danti, "Differential activity of catalase and superoxide dismutase in seedlings and in vitro micropropagated oak (Quercus robur L.)," Plant Cell Reports, vol. 20, no. 2, pp. 169-174, 2001.

[178] C. Bowler, M. Van Montagu, and D. Inzé, "Superoxide dismutase and stress tolerance," Annual Review of Plant Physiology and Plant Molecular Biology, vol. 43, no. 1, pp. 83116, 1992.

[179] C. Jackson, J. Dench, A. L. Moore, B. Halliwell, C. H. Foyer, and D. O. Hall, "Subcellular localisation and identification of superoxide dismutase in the leaves of higher plants," European Journal of Biochemistry, vol. 91, no. 2, pp. 339-344, 1978.

[180] S. Kanematsu and K. Asada, "Cuzn-superoxide dismutases in rice: occurrence of an active, monomeric enzyme and two types of isozyme in leaf and non-photosynthetic tissues," Plant and Cell Physiology, vol. 30, no. 3, pp. 381-391, 1989.

[181] P. Bueno, J. Varela, G. Gimenez-Gallego, and L. A. Del Rio, "Peroxisomal copper, zinc superoxide dismutase. Characterization of the isoenzyme from watermelon cotyledons," Plant Physiology, vol. 108, no. 3, pp. 1151-1160, 1995.

[182] L. A. Del Río, G. M. Pastori, J. M. Palma et al., "The activated oxygen role of peroxisomes in senescence," Plant Physiology, vol. 116, no. 4, pp. 1195-1200, 1998.

[183] A. S. Gupta, J. L. Heinen, A. S. Holaday, J. J. Burke, and R. D. Allen, "Increased resistance to oxidative stress in transgenic plants that overexpress chloroplastic $\mathrm{Cu} / \mathrm{Zn}$ superoxide dismutase," Proceedings of the National Academy of Sciences of the United States of America, vol. 90, no. 4, pp. 1629-1633, 1993.

[184] G. Scandalios, L. Guan, and A. N. Polidoros, "Catalases in plants: gene structure, properties, regulation and expression," 
in Oxidative Stress and the Molecular Biology of Antioxidants Defenses, J. G. Scandalios, Ed., pp. 343-406, Cold Spring Harbor Laboratory Press, New York, NY, USA, 1997.

[185] F. J. Corpas, J. M. Palma, L. M. Sandalio, R. Valderrama, J. B. Barroso, and L. A. del Río, "Peroxisomal xanthine oxidoreductase: characterization of the enzyme from pea (Pisum sativum L.) leaves," Journal of Plant Physiology, vol. 165 , no. 13, pp. 1319-1330, 2008.

[186] A. Mhamdi, G. Queval, S. Chaouch, S. Vanderauwera, F. Van Breusegem, and G. Noctor, "Catalase function in plants: a focus on Arabidopsis mutants as stress-mimic models," Journal of Experimental Botany, vol. 61, no. 15, pp. 41974220, 2010.

[187] H. Willekens, D. Inze, M. Van Montagu, and W. Van Camp, "Catalases in plants," Molecular Breeding, vol. 1, no. 3, pp. 207-228, 1995.

[188] N. Mallick and F. H. Mohn, "Reactive oxygen species: response of algal cells," Journal of Plant Physiology, vol. 157, no. 2, pp. 183-193, 2000.

[189] R. Moussa and S. M Abdel-Aziz, "Comparative response of drought tolerant and drought sensitive maize genotypes to water stress," Australian Journal of Crop Sciences, vol. 1, no. 1, pp. 31-36, 2008.

[190] H. Willekens, S. Chamnongpol, M. Davey et al., "Catalase is a sink for $\mathrm{H}_{2} \mathrm{O}_{2}$ and is indispensable for stress defence in C-3 plants," EMBO Journal, vol. 16, no. 16, pp. 4806-4816, 1997.

[191] Z. Guan, T. Chai, Y. Zhang, J. Xu, and W. Wei, "Enhancement of Cd tolerance in transgenic tobacco plants overexpressing a Cd-induced catalase cDNA," Chemosphere, vol. 76, no. 5, pp. 623-630, 2009.

[192] D. J. Schuller, N. Ban, R. B. Van Huystee, A. McPherson, and T. L. Poulos, "The crystal structure of peanut peroxidase," Structure, vol. 4, no. 3, pp. 311-321, 1996.

[193] K. Asada, "Ascorbate peroxidase: a hydrogen peroxide scavenging enzyme in plants," Physiologia Plantarum, vol. 85, no. 2, pp. 235-241, 1992.

[194] K. Kobayashi, Y. Kumazawa, K. Miwa, and S. Yamanaka, " $\varepsilon$-( $\gamma$-Glutamyl)lysine cross-links of spore coat proteins and transglutaminase activity in Bacillus subtilis," FEMS Microbiology Letters, vol. 144, no. 2-3, pp. 157-160, 1996.

[195] J. Vangronsveld and H. Clijsters, "Toxic effects of metals," in Plants and the Chemical Elements. Biochemistry, Uptake, Tolerance and Toxicity, M. E. Farago, Ed., pp. 150-177, VCH Publishers, Weinheim, Germany, 1994.

[196] K. Radotić, T. Dučić, and D. Mutavdžić, "Changes in peroxidase activity and isoenzymes in spruce needles after exposure to different concentrations of cadmium," Environmental and Experimental Botany, vol. 44, no. 2, pp. 105-113, 2000.

[197] H. Tayefi-Nasrabadi, G. Dehghan, B. Daeihassani, A. Movafegi, and A. Samadi, "Some biochemical properties of guaiacol peroxidases as modified by salt stress in leaves of salt-tolerant and salt-sensitive safflower (Carthamus tinctorius L.cv.) cultivars," African Journal of Biotechnology, vol. 10, no. 5, pp. 751-763, 2011.

[198] A. Jiménez, J. A. Hernández, L. A. Del Río, and F. Sevilla, "Evidence for the presence of the ascorbate-glutathione cycle in mitochondria and peroxisomes of pea leaves," Plant Physiology, vol. 114, no. 1, pp. 275-284, 1997.

[199] J. E. Pallanca and N. Smirnoff, "The control of ascorbic acid synthesis and turnover pea seedlings," Journal of Experimental Botany, vol. 51, no. 345, pp. 669-674, 2000.

[200] K. G. Welinder, "Superfamily of plant, fungal and bacterial peroxidases," Current Opinion in Structural Biology, vol. 2, no. 3, pp. 388-393, 1992.
[201] W. R. Patterson and T. L. Poulos, "Crystal structure of recombinant pea cytosolic ascorbate peroxidase," Biochemistry, vol. 34, no. 13, pp. 4331-4341, 1995.

[202] R. Madhusudhan, T. Ishikawa, Y. Sawa, S. Shigeoka, and H. Shibata, "Characterization of an ascorbate peroxidase in plastids of tobacco BY-2 cells," Physiologia Plantarum, vol. 117, no. 4, pp. 550-557, 2003.

[203] P. Sharma and R. S. Dubey, "Ascorbate peroxidase from rice seedlings: properties of enzyme isoforms, effects of stresses and protective roles of osmolytes," Plant Science, vol. 167, no. 3, pp. 541-550, 2004.

[204] Y. Nakano and K. Asada, "Purification of ascorbate peroxidase in spinach chloroplasts; its inactivation in ascorbatedepleted medium and reactivation by monodehydroascorbate radical," Plant and Cell Physiology, vol. 28, no. 1, pp. 131-140, 1987.

[205] R. Mittler and B. A. Zilinskas, "Molecular cloning and characterization of a gene encoding pea cytosolic ascorbate peroxidase," Journal of Biological Chemistry, vol. 267, no. 30, pp. 21802-21807, 1992.

[206] T. Ishikawa, K. Yoshimura, K. Sakai, M. Tamoi, T. Takeda, and S. Shigeoka, "Molecular characterization and physiological role of a glyoxysome-bound ascorbate peroxidase from spinach," Plant and Cell Physiology, vol. 39, no. 1, pp. 23-34, 1998.

[207] J. Wang, H. Zhang, and R. D. Allen, "Overexpression of an Arabidopsis peroxisomal ascorbate peroxidase gene in tobacco increases protection against oxidative stress," Plant and Cell Physiology, vol. 40, no. 7, pp. 725-732, 1999.

[208] Y. C. Boo and J. Jung, "Water deficit - Induced oxidative stress and antioxidative defenses in rice plants," Journal of Plant Physiology, vol. 155, no. 2, pp. 255-261, 1999.

[209] Y. Wang, M. Wisniewski, R. Meilan, M. Cui, R. Webb, and L. Fuchigami, "Overexpression of cytosolic ascorbate peroxidase in tomato confers tolerance to chilling and salt stress," Journal of the American Society for Horticultural Science, vol. 130, no. 2, pp. 167-173, 2005.

[210] Y. Yabuta, T. Motoki, K. Yoshimura, T. Takeda, T. Ishikawa, and S. Shigeoka, "Thylakoid membrane-bound ascorbate peroxidase is a limiting factor of antioxidative systems under photo-oxidative stress," Plant Journal, vol. 32, no. 6, pp. 915925, 2002.

[211] T. Ushimaru, Y. Maki, S. Sano, K. Koshiba, K. Asada, and H. Tsuji, "Induction of Enzymes Involved in the AscorbateDependent Antioxidative System, Namely, Ascorbate Peroxidase, Monodehydroascorbate Reductase and Dehydroascorbate Reductase, after Exposure to Air of Rice (Oryza sativa) Seedlings Germinated under Water," Plant and Cell Physiology, vol. 38, no. 5, pp. 541-549, 1997.

[212] M. A. Hossain and K. Asada, "Monodehydroascorbate reductase from cucumber is a flavin adenine dinucleotide enzyme," Journal of Biological Chemistry, vol. 260, no. 24, pp. 12920 12926, 1985.

[213] Y. Sakihama, J. Mano, S. Sano, K. Asada, and H. Yamasaki, "Reduction of phenoxyl radicals mediated by monodehydroascorbate reductase," Biochemical and Biophysical Research Communications, vol. 279, no. 3, pp. 949-954, 2000.

[214] M. A. Hossain, Y. Nakano, and K. Asada, "Monodehydroascorbate reductase in spinach chloroplasts and its participation in regeneration of ascorbate for scavenging hydrogen peroxide," Plant and Cell Physiology, vol. 25, no. 3, pp. 385395, 1984.

[215] D. A. Dalton, L. M. Baird, L. Langeberg et al., "Subcellular localization of oxygen defense enzymes in soybean (Glycine 
max [L.] Merr.) root nodules," Plant Physiology, vol. 102, no. 2, pp. 481-489, 1993.

[216] C. Miyake, U. Schreiber, H. Hormann, S. Sano, and K. Asada, "The FAD-enzyme monodehydroascorbate radical reductase mediates photoproduction of superoxide radicals in spinach thylakoid membranes," Plant and Cell Physiology, vol. 39, no. 8, pp. 821-829, 1998.

[217] A. E. Eltayeb, N. Kawano, G. H. Badawi et al., "Overexpression of monodehydroascorbate reductase in transgenic tobacco confers enhanced tolerance to ozone, salt and polyethylene glycol stresses," Planta, vol. 225, no. 5, pp. 1255 1264, 2007.

[218] F. Li, Q. Y. Wu, Y. L. Sun, L. Y. Wang, X. H. Yang, and Q. W. Meng, "Overexpression of chloroplastic monodehydroascorbate reductase enhanced tolerance to temperature and methyl viologen-mediated oxidative stresses," Physiologia Plantarum, vol. 139, no. 4, pp. 421-434, 2010.

[219] Z. Chen, T. E. Young, J. Ling, S. C. Chang, and D. R. Gallie, "Increasing vitamin C content of plants through enhanced ascorbate recycling," Proceedings of the National Academy of Sciences of the United States of America, vol. 100, no. 6, pp. 3525-3530, 2003.

[220] A. Qin, Q. Shi, and X. Yu, "Ascorbic acid contents in transgenic potato plants overexpressing two dehydroascorbate reductase genes," Molecular Biology Reports, vol. 38, no. 3, pp. 1557-1566, 2011.

[221] M. A. Hossain and K. Asada, "Purification of dehydroascorbate reductase from spinach and its characterization as a thiol enzyme," Plant and Cell Physiology, vol. 25, no. 1, pp. 85-92, 1984.

[222] S. Dipierro and G. Borraccino, "Dehydroascorbate reductase from potato tubers," Phytochemistry, vol. 30, no. 2, pp. 427$429,1991$.

[223] S. Yoshida, M. Tamaoki, T. Shikano et al., "Cytosolic dehydroascorbate reductase is important for ozone tolerance in Arabidopsis thaliana," Plant and Cell Physiology, vol. 47, no. 2, pp. 304-308, 2006.

[224] M. C. Rubio, P. Bustos-Sanmamed, M. R. Clemente, and M. Becana, "Effects of salt stress on the expression of antioxidant genes and proteins in the model legume Lotus japonicus," New Phytologist, vol. 181, no. 4, pp. 851-859, 2009.

[225] A. E. Eltayeb, S. Yamamoto, M. E.E. Habora, L. Yin, H. Tsujimoto, and K. Tanaka, "Transgenic potato overexpressing Arabidopsis cytosolic AtDHAR1 showed higher tolerance to herbicide, drought and salt stresses," Breeding Science, vol. 61, no. 1, pp. 3-10, 2011.

[226] S. Ghisla and V. Massey, "Mechanisms of flavoproteincatalyzed reactions," European Journal of Biochemistry, vol. 181, no. 1, pp. 1-17, 1989.

[227] E. A. Edwards, S. Rawsthorne, and P. M. Mullineaux, "Subcellular distribution of multiple forms of glutathione reductase in leaves of pea (Pisum sativum L.)," Planta, vol. 180, no. 2, pp. 278-284, 1990.

[228] G. M. Pastori and V. S. Trippi, "Oxidative stress induces high rate of glutathione reductase synthesis in a drought-resistant maize strain," Plant and Cell Physiology, vol. 33, no. 7, pp. 957-961, 1992.

[229] D. -F. Shu, L. -Y. Wang, M. Duan, Y. -S. Deng, and Q. -W. Meng, "Antisense-mediated depletion of tomato chloroplast glutathione reductase enhances susceptibility to chilling stress," Plant Physiology and Biochemistry, vol. 49, no. 10, pp. 1228-1237, 2011.
[230] M. Aono, A. Kubo, H. Saji, K. Tanaka, and N. Kondo, "Enhanced tolerance to photooxidative stress of transgenic Nicotiana tabacum with high chloroplastic glutathione reductase activity," Plant and Cell Physiology, vol. 34, no. 1, pp. 129-135, 1993.

[231] M. J. Tseng, C. W. Liu, and J. C. Yiu, “Tolerance to sulfur dioxide in transgenic Chinese cabbage transformed with both the superoxide dismutase containing manganese and catalase genes of Escherichia coli," Scientia Horticulturae, vol. 115, no. 2, pp. 101-110, 2008.

[232] S. C. Lee, S. Y. Kwon, and S. R. Kim, "Ectopic expression of a cold-responsive CuZn superoxide dismutase gene, SodCc1, in transgenic rice (Oryza sativa L.)," Journal of Plant Biology, vol. 52, no. 2, pp. 154-160, 2009.

[233] M. Aono, H. Saji, A. Sakamoto, K. Tanaka, N. Kondo, and Tanaka, "Paraquat tolerance of transgenic Nicotiana tabacum with enhanced activities of glutathione reductase and superoxide dismutase," Plant and Cell Physiology, vol. 36, no. 8, pp. 1687-1691, 1995.

[234] S. Y. Kwon, Y. J. Jeong, H. S. Lee et al., "Enhanced tolerances of transgenic tobacco plants expressing both superoxide dismutase and ascorbate peroxidase in chloroplasts against methyl viologen-mediated oxidative stress," Plant, Cell and Environment, vol. 25, no. 7, pp. 873-882, 2002.

[235] S. Lim, Y. H. Kim, S. H. Kim et al., "Enhanced tolerance of transgenic sweetpotato plants that express both CuZnSOD and APX in chloroplasts to methyl viologen-mediated oxidative stress and chilling," Molecular Breeding, vol. 19, no. 3, pp. 227-239, 2007.

[236] S. S. Kwak, S. Lim, L. Tang, S. Y. Kwon, and H. S. Lee, "Enhanced tolerance of transgenic crops expressing both SOD and APX in chloroplasts to multiple environmental stress," in Salinity and Water Stress, M. Ashraf, M. Ozturk, and H. R. Athar, Eds., pp. 197-203, Springer, Netherland, 2009.

[237] K. Asada, "The water-water cycle in chloroplasts: scavenging of active oxygens and dissipation of excess photons," Annual Review of Plant Biology, vol. 50, pp. 601-639, 1999.

[238] K. Biehler and H. Fock, "Evidence for the contribution of the Mehler-peroxidase reaction in dissipating excess electrons in drought-stressed wheat," Plant Physiology, vol. 112, no. 1, pp. 265-272, 1996.

[239] C. H. Foyer and G. Noctor, "Oxygen processing in photosynthesis: regulation and signalling," New Phytologist, vol. 146, no. 3, pp. 359-388, 2000.

[240] R. K. Sairam, P. S. Deshmukh, and D. C. Saxena, "Role of antioxidant systems in wheat genotypes tolerance to water stress," Biologia Plantarum, vol. 41, no. 3, pp. 387-394, 1998.

[241] S. Wang, D. Liang, C. Li, Y. Hao, F. Ma, and H. Shu, "Influence of drought stress on the cellular ultrastructure and antioxidant system in leaves of drought-tolerant and drought-sensitive apple rootstocks," Plant Physiology and Biochemistry, vol. 51, pp. 81-89, 2012.

[242] J. A. Hernández, A. Jiménez, P. Mullineaux, and F. Sevilla, "Tolerance of pea (Pisum sativum L.) to long-term salt stress is associated with induction of antioxidant defences," Plant, Cell and Environment, vol. 23, no. 8, pp. 853-862, 2000.

[243] U. Perez-Lopez, A. Robredo, M. Lacuesta et al., "The oxidative stress caused by salinity in two barley cultivars is mitigated by elevated $\mathrm{CO}_{2}$," Physiologia Plantarum, vol. 135, no. 1, pp. 29-42, 2009.

[244] N. Karray-Bouraoui, F. Harbaoui, M. Rabhi et al., "Different antioxidant responses to salt stress in two different 
provenances of Carthamus tinctorius L," Acta Physiologiae Plantarum, vol. 33, no. 4, pp. 1435-1444, 2011.

[245] X. Wang, P. Yang, Q. Gao et al., "Proteomic analysis of the response to high-salinity stress in Physcomitrella patens," Planta, vol. 228, no. 1, pp. 167-177, 2008.

[246] H. Vaidyanathan, P. Sivakumar, R. Chakrabarty, and G. Thomas, "Scavenging of reactive oxygen species in $\mathrm{NaCl}$ stressed rice (Oryza sativa L.) - Differential response in salttolerant and sensitive varieties," Plant Science, vol. 165, no. 6, pp. 1411-1418, 2003.

[247] A. Shalata, V. Mittova, M. Volokita, M. Guy, and M. Tal, "Response of the cultivated tomato and its wild salt-tolerant relative Lycopersicon pennellii to salt-dependent oxidative stress: the root antioxidative system," Physiologia Plantarum, vol. 112, no. 4, pp. 487-494, 2001.

[248] A. Hediye Sekmen, I. Türkan, and S. Takio, "Differential responses of antioxidative enzymes and lipid peroxidation to salt stress in salt-tolerant Plantago maritima and saltsensitive Plantago media," Physiologia Plantarum, vol. 131, no. 3, pp. 399-411, 2007.

[249] B. A. Logan, D. Kornyeyev, J. Hardison, and A. S. Holaday, "The role of antioxidant enzymes in photoprotection," Photosynthesis Research, vol. 88, no. 2, pp. 119-132, 2006.

[250] Y. H. Zhou, J. Q. Yu, W. H. Mao, L. F. Huang, X. S. Song, and S. Nogués, "Genotypic variation of Rubisco expression, photosynthetic electron flow and antioxidant metabolism in the chloroplasts of chill-exposed cucumber plants," Plant and Cell Physiology, vol. 47, no. 2, pp. 192-199, 2006.

[251] T. K. Prasad, "Role of catalase in inducing chilling tolerance in pre-emergent maize seedlings," Plant Physiology, vol. 114, no. 4, pp. 1369-1376, 1997.

[252] Y. Zhang, H. R. Tang, and Y. Luo, "Variation in antioxidant enzyme activities of two strawberry cultivars with shortterm low temperature stress," World Journal of Agricultural Sciences, vol. 4, no. 4, pp. 458-462, 2008.

[253] L. S. Jahnke, M. R. Hull, and S. P. Long, "Chilling stress and oxygen metabolizing enzymes in Zea mays and Zea diploperennis," Plant, Cell and Environment, vol. 14, no. 1, pp. 97-104, 1991.

[254] D. M. Hodges, C. J. Andrews, D. A. Johnson, and R. I. Hamilton, "Antioxidant compound responses to chilling stress in differentially sensitive inbred maize lines," Physiologia Plantarum, vol. 98, no. 4, pp. 685-692, 1996.

[255] M. Huang and Z. Guo, "Responses of antioxidative system to chilling stress in two rice cultivars differing in sensitivity," Biologia Plantarum, vol. 49, no. 1, pp. 81-84, 2005.

[256] D. E. Salt, M. Blaylock, N. P. B. A. Kumar et al., "Phytoremediation: a novel strategy for the removal of toxic metals from the environment using plants," Biotechnology, vol. 13, no. 5, pp. 468-474, 1995.

[257] S. Mishra and R. S. Dubey, "Heavy metal toxicity induced alterations in photosynthetic metabolism in plants," in Handbook of Photosynthesis, M. Pessarakli, Ed., pp. 845-863, CRC Press, Taylor and Francis Publishing Company, Fla, USA, 2nd edition, 2005.

[258] S. Gallego, M. Benavides, and M. Tomaro, "Involvement of an antioxidant defence system in the adaptive response to heavy metal ions in Helianthus annuus L. cells," Plant Growth Regulation, vol. 36, no. 3, pp. 267-273, 2002.

[259] F. Vinit-Dunand, D. Epron, B. Alaoui-Sossé, and P. M. Badot, "Effects of copper on growth and on photosynthesis of mature and expanding leaves in cucumber plants," Plant Science, vol. 163, no. 1, pp. 53-58, 2002.
[260] M. Moustakas, T. Lanaras, L. Symeonidis, and S. Karataglis, "Growth and some photosynthetic characteristics of field grown Avena sativa under copper and lead stress," Photosynthetica, vol. 30, no. 3, pp. 389-396, 1994.

[261] A. Źróbek-Sokolnik, H. Asard, K. Górska-Koplińska, and R. J. Górecki, "Cadmium and zinc-mediated oxidative burst in tobacco BY-2 cell suspension cultures," Acta Physiologiae Plantarum, vol. 31, no. 1, pp. 43-49, 2009.

[262] S. M. Gallego, M. P. Benavides, and M. L. Tomaro, "Effect of heavy metal ion excess on sunflower leaves: evidence for involvement of oxidative stress," Plant Science, vol. 121, no. 2, pp. 151-159, 1996.

[263] J. E. J. Weckx and H. M. M. Clijsters, "Oxidative damage and defense mechanisms in primary leaves of Phaseolus vulgaris as a result of root assimilation of toxic amounts of copper," Physiologia Plantarum, vol. 96, no. 3, pp. 506-512, 1996.

[264] Y. Yamamoto, A. Hachiya, and H. Matsumoto, "Oxidative damage to membranes by a combination of aluminum and iron in suspension-cultured tobacco cells," Plant and Cell Physiology, vol. 38, no. 12, pp. 1333-1339, 1997.

[265] S. S. Sharma and K. J. Dietz, "The relationship between metal toxicity and cellular redox imbalance," Trends in Plant Science, vol. 14, no. 1, pp. 43-50, 2009.

[266] L. M. Sandalio, M. Rodríguez-Serrano, L. A. del Río, and M. C. Romero-Puertas, "Reactive oxygen species and signaling in cadmium toxicity," in Reactive Oxygen Species in Plant Signaling, L. A. Rio and A. Puppo, Eds., pp. 175-189, Springer, Berlin, Germany, 2009.

[267] A. Giannakoula, M. Moustakas, T. Syros, and T. Yupsanis, "Aluminum stress induces up-regulation of an efficient antioxidant system in the Al-tolerant maize line but not in the Al-sensitive line," Environmental and Experimental Botany, vol. 67, no. 3, pp. 487-494, 2010.

[268] S. Srivastava, A. K. Srivastava, P. Suprasanna, and S. F. D'souza, "Comparative antioxidant profiling of tolerant and sensitive varieties of Brassica juncea L. to arsenate and arsenite exposure," Bulletin of Environmental Contamination and Toxicology, vol. 84, no. 3, pp. 342-346, 2010.

[269] M. Blumthaler and W. Ambach, "Indication of increasing solar ultraviolet-B radiation flux in alpine regions," Science, vol. 248, no. 4952, pp. 206-208, 1990.

[270] D. J. Allen, I. F. Mckee, P. K. Farage, and N. R. Baker, "Analysis of limitations to $\mathrm{CO}_{2}$ assimilation on exposure of leaves of two Brassica napus cultivars to UV-B," Plant, Cell and Environment, vol. 20, no. 5, pp. 633-640, 1997.

[271] J. He, L. K. Huang, W. S. Chow, M. L. Whitecross, and J. M Anderson, "Effects of supplementary ultraviolet-B radiation on rice and pea plants," Australian Journal of Plant Physiology, vol. 20, no. 2, pp. 129-142, 1993.

[272] A. Strid, W. S. Chow, and J. M. Anderson, "UV-B damage and protection at the molecular level in plants," Photosynthesis Research, vol. 39, no. 3, pp. 475-489, 1994.

[273] N. Doke, "Generation of superoxide anion by potato tuber protoplasts during the hypersensitive response to hyphal wall components of Phytophthora infestans and specific inhibition of the reaction by suppressors of hypersensitivity," Physiological Plant Pathology, vol. 23, no. 3, pp. 359-367, 1983.

[274] J. J. Grant, B. W. Yun, and G. J. Loake, "Oxidative burst and cognate redox signalling reported by luciferase imaging: identification of a signal network that functions independently of ethylene, SA and Me-JA but is dependent on MAPKK activity," Plant Journal, vol. 24, no. 5, pp. 569-582, 2000. 
[275] J. M. Chittoor, J. E. Leach, and F. F. White, "Differential induction of a peroxidase gene family during infection of rice by Xanthomonas oryzae pv. oryzae," Molecular Plant-Microbe Interactions, vol. 10, no. 7, pp. 861-871, 1997.

[276] K. Sasaki, T. Iwai, S. Hiraga et al., "Ten rice peroxidases redundantly respond to multiple stresses including infection with rice blast fungus," Plant and Cell Physiology, vol. 45, no. 10, pp. 1442-1452, 2004.

[277] H. Abdollahi and Z. Ghahremani, "The role of chloroplasts in the interaction between Erwinia amylovora and host plants," Acta Horticulturae, vol. 896, pp. 215-221, 2011.

[278] Y. Liu, D. Ren, S. Pike, S. Pallardy, W. Gassmann, and S. Zhang, "Chloroplast-generated reactive oxygen species are involved in hypersensitive response-like cell death mediated by a mitogen-activated protein kinase cascade," Plant Journal, vol. 51, no. 6, pp. 941-954, 2007.

[279] R. Mittler, E. H. Herr, B. L. Orvar et al., "Transgenic tobacco plants with reduced capability to detoxify reactive oxygen intermediates are hyperresponsive to pathogen infection," Proceedings of the National Academy of Sciences of the United States of America, vol. 96, no. 24, pp. 14165-14170, 1999. 

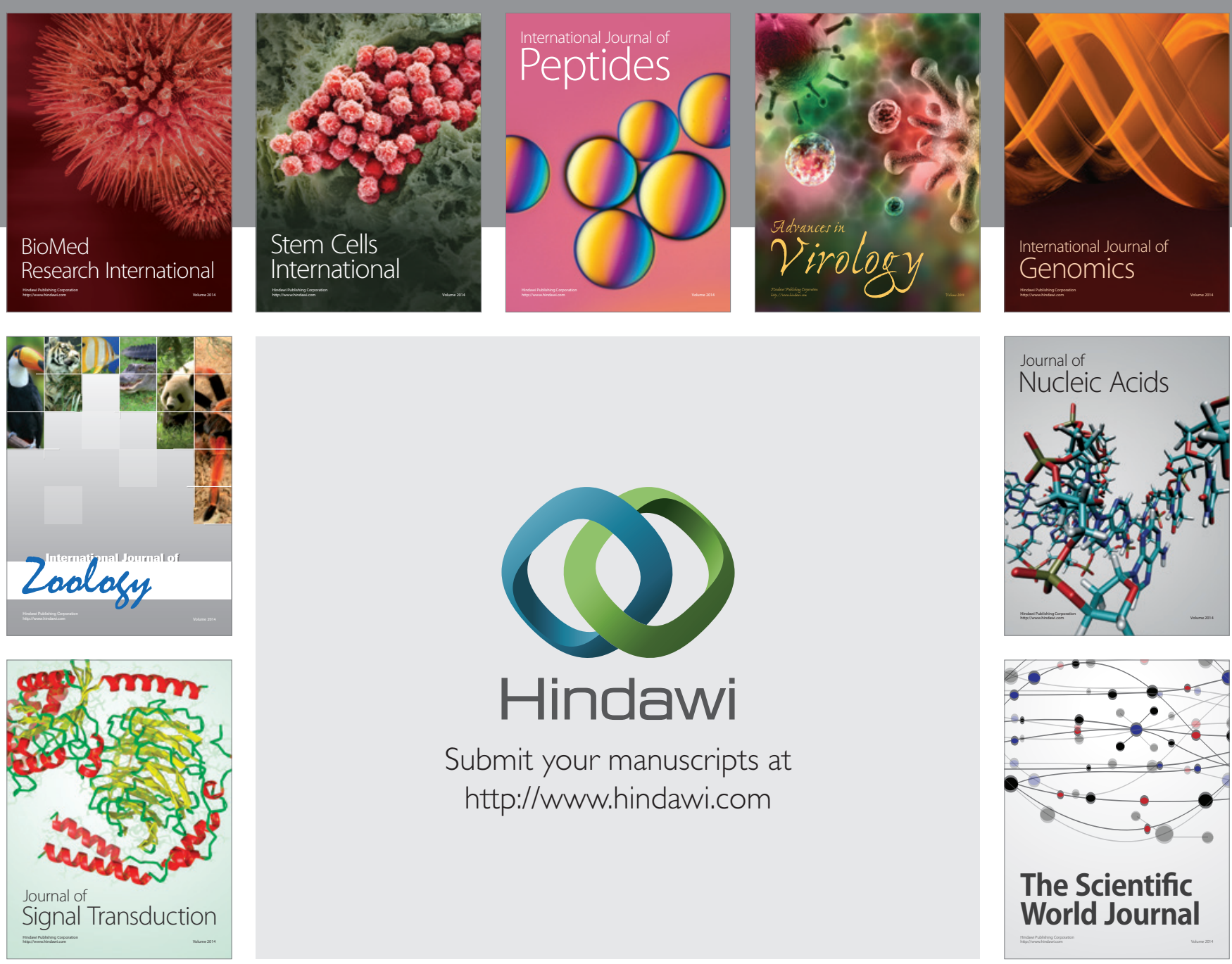

Submit your manuscripts at

http://www.hindawi.com
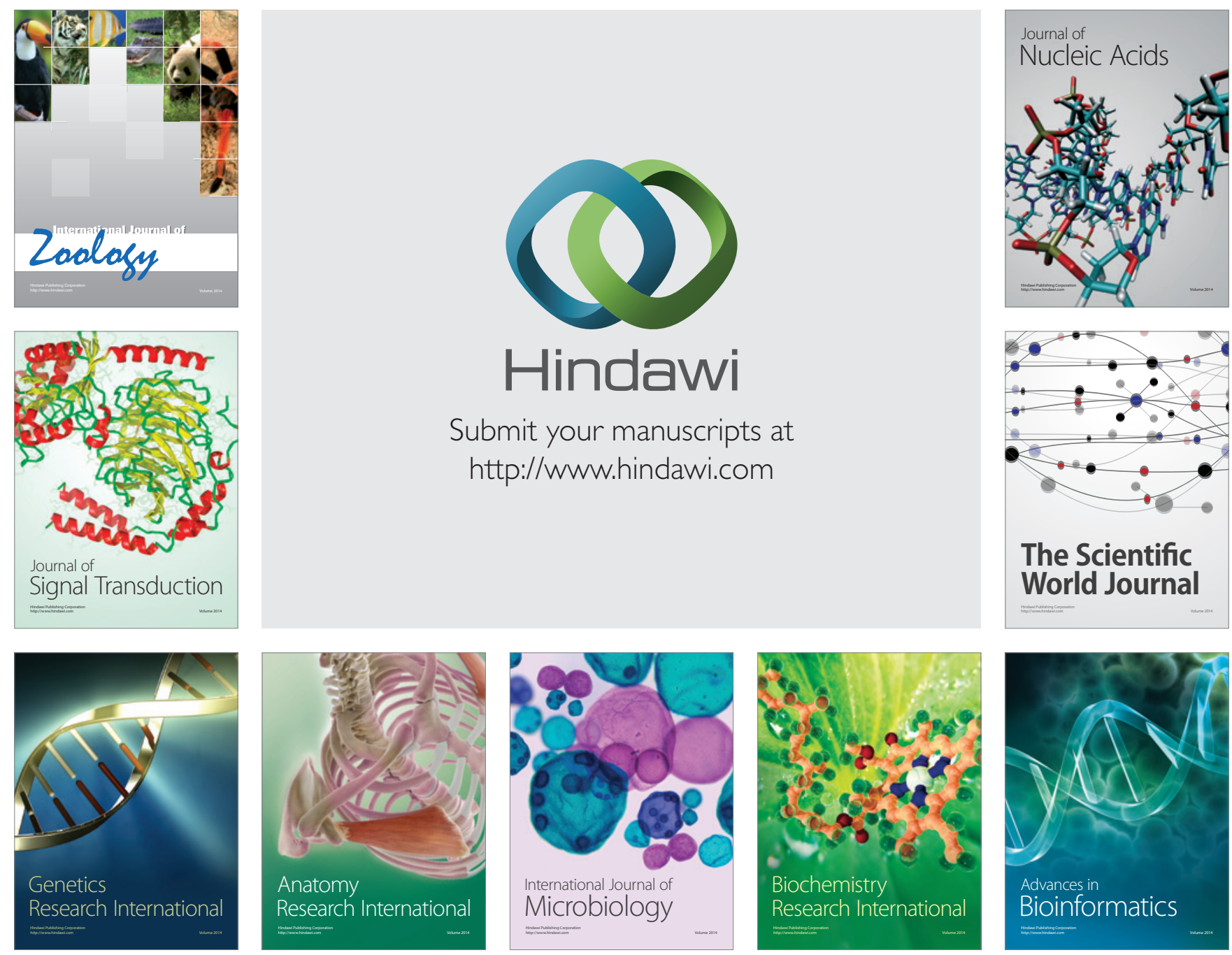

The Scientific World Journal
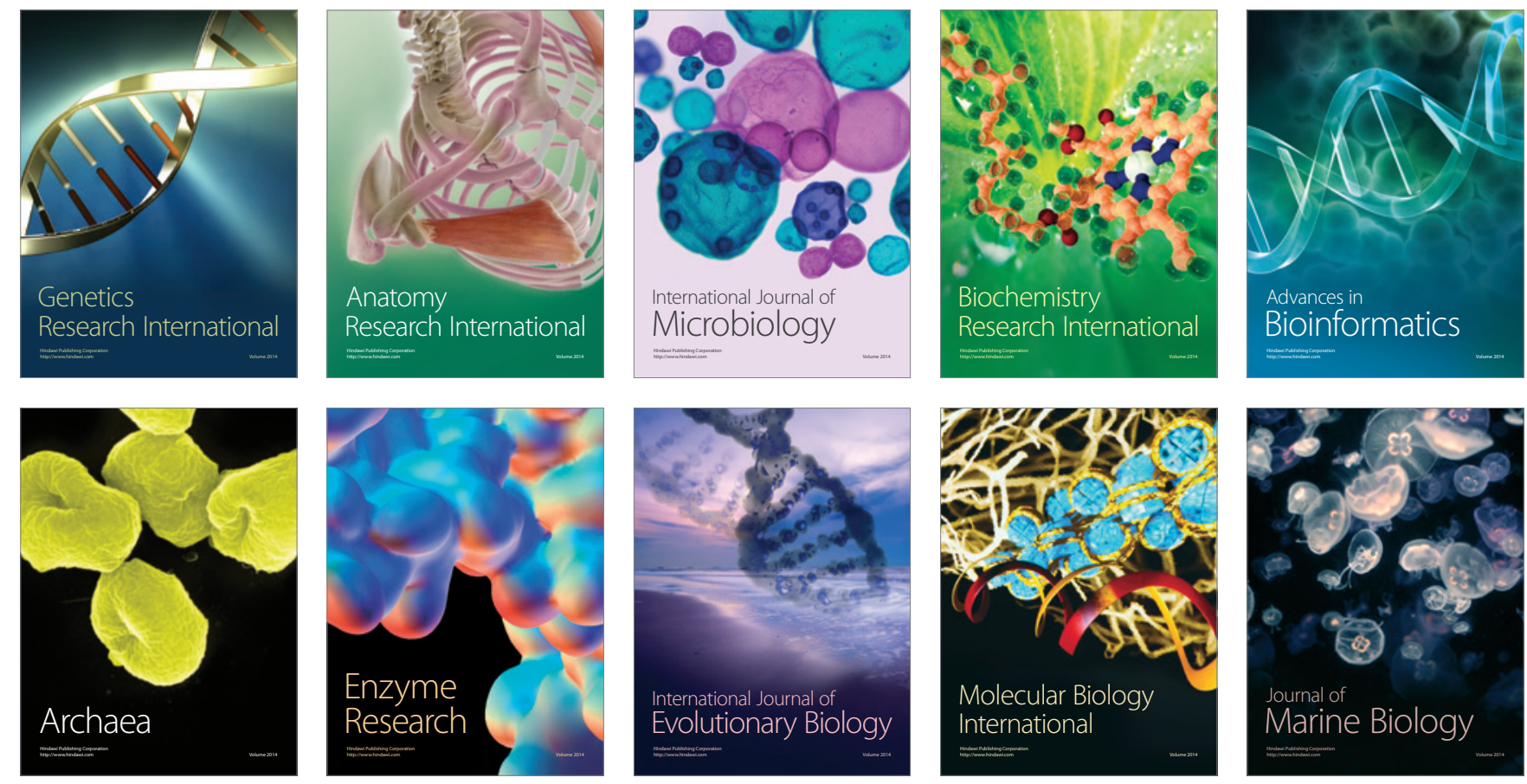